\title{
Criterios de traducción bíblica-litúrgica al tseltal, al náhuatl y al español minorizado: un paradigma de traducción activista'
}

\author{
Gunther Dietz \\ gdietz@uv.mx \\ Instituto de Investigaciones en Educación, Universidad Veracruzana, México
}

\begin{abstract}
Resumen
El objetivo de este artículo de investigación original es problematizar el fenómeno del reconocimiento y la revitalización de las lenguas indígenas y minoritarias que tiene lugar en México, Latinoamérica y Estados Unidos como resultado del impulso programático originado en la Iglesia Católica para traducir textos litúrgicos y bíblicos con la participación de las comunidades originarias. En específico, consideramos los criterios de traducción de los equipos lingǘsticos conformados por hablantes originarios que han trabajado con las lenguas tseltal y náhuatl, en un periodo que abarca los últimos 40 y 6 años, respectivamente, y los cotejamos con los criterios seguidos por el equipo lingǘstico que ha trabajado en los últimos 14 años con el español como lengua minoritaria en los Estados Unidos. La metodología analítica es de carácter contrastivo-comparatista, basada en observación crítica en campo, entrevistas a personajes clave y estudio de documentos de primera mano emanados de los talleres del Equipo Nacional de Traductores del Náhuatl realizados entre 2017 y 2018, así como del Encuentro de Traductores de la Biblia y la Liturgia a los Idiomas Indígenas convocado por la Conferencia del Episcopado Mexicano (CEM) en 2018. Nuestra problematización de la traducción cultural, como actividad central de una lucha por la dignificación de grupos étnicos es vista desde los lentes de la decolonialidad latinoamericana y una teología india que nosotros enmarcamos en una teología poscolonial. El papel agencial de la CEM, las asimetrías formativas de los traductores, la libertad organizativa, la necesidad de establecer procesos y criterios de traducción, así como los puntos de encuentro y disenso en ellos son los principales resultados que se reportan.
\end{abstract}

Palabras clave: traducción intercultural religiosa, traducción activista, traducción contrahegemónica, formación de traductores, teología poscolonial.

$1 \mathrm{El}$ artículo presenta resultados parciales del Proyecto de Investigación-sistematización de experiencias educativas de traducción y comunicación intercultural en los Talleres de Lengua y Cultura Náhuatl del Equipo Nacional de Traductores del Náhuatl (ENTN) de la Conferencia del Episcopado Mexicano (CEM) que se realiza en el Instituto de Investigaciones en Educación de la Universidad Veracruzana bajo el registro SIREI 280732018111. 


\section{Criteria for Biblical and Liturgical Translation into Tseltal, Nahuatl, and Spanish as a minority language: An Activist Translation Paradigm}

This paper aims at problematizing the issue of acknowledging and reviving native and minority languages in Mexico, Latin America, and the United States as a result of a programmatical boost by the Catholic Church looking to translate liturgical and biblical texts together with the participation of aboriginal communities. Specifically, we examined the translation criteria applied by linguistic teams, consisting of native speakers who have been working with Tseltal and Nahuatl languages for the last 40 and 6 years, respectively. Their criteria were compared with criteria followed by the linguistic team that has been working for the last 14 years with Spanish as a minor language in the u.s.a. The method of analysis is contrastive-comparative, based on critical observation in the field, interviews with main participants, and the study of primary sources. That information was taken at workshops held by the national Nahuatl translation team, between 2017 and 2018, and from the Indigenous Language Bible/Liturgical Translators' Meeting hosted by CEM (Mexican Conference of Bishops, as per its initials in Spanish) in Mexico, 2018. Problematizing cultural translation, as a key action in the struggle to dignify ethnic groups, is viewed under the lenses of Latin American decoloniality and indigenous theology, which we put within the framework of postcolonial theology. CEM's agential role, translators' training asymmetries, freedom of organization, the need to define translations processes and criteria, including the points of agreement and disagreement, are among the main findings reported.

Keywords: religious intercultural translation, activist translation, counter-hegemonic translation, translators' training, post-colonial theology.

\section{Critères de traduction biblico-liturgique en tseltal, nahuatl et espagnol comme langue minoritaire: un paradigme de traduction activiste}

L'objectif de cet article consiste à problématiser le phénomène de reconnaissance et de revitalisation des langues indigènes et minoritaires au Mexique, en Amérique Latine et aux États-Unis à la suite de l'impulsion programmatique née au sein de l'Église catholique pour traduire des textes liturgiques et bibliques avec la participation des communautés autochtones. Plus précisément, on considère les critères de traduction des équipes linguistiques composées de locuteurs natifs qui ont travaillé avec les langues tseltal et nahuatl, dans une période qui couvre 40 ans et 6 ans, respectivement. Nous les comparons avec les critères suivis par l'équipe linguistique qui a travaillé ces 14 dernières années sur l'espagnol en tant que langue minoritaire aux États-Unis. La méthodologie analytique est de nature contrastive-comparative, basée sur l'observation critique sur le terrain, sur des entretiens aux personnages clés et sur l'étude de documents de première main émanant des Ateliers de l'Équipe Nationale de Traducteurs de Nahuatl, réalisés entre 2017 et 2018, ainsi que de la Rencontre des Traducteurs de la Bible et de la Liturgie des Langues Indigènes convoquée par la Conférence de l'Épiscopat Mexicain à Mexico en 2018. Notre problématisation de la traduction culturelle en tant qu'activité centrale d'une lutte pour la dignité des groupes ethniques est vue sous l'angle de la décolonialité latino-américaine et d'une théologie indienne que nous avons encadrée dans une théologie postcoloniale. Le rôle principal de la CEM, les asymétries formatives des traducteurs, la liberté d'organisation, la nécessité d'établir des processus et des critères de traduction, ainsi que les points de rencontre et de divergence qui s'y trouvent, sont les principaux résultats rapportés.

Mots-clés: traduction religieuse interculturelle, traduction activiste, traduction anti-hégémonique, formation de traducteurs, théologie postcoloniale 


\section{Introducción}

Nuestra investigación reporta los resultados de la primera fase de un proyecto macro que busca dar cuenta de experiencias educativas de traducción y comunicación intercultural en el caso de la traducción textual a lenguas originarias en el ámbito religioso (véase la nota 1). Esta fase corresponde a la exploración del marco global de políticas y lineamientos institucionales que propician tales acciones en comunidades específicas y aterrizan en prácticas simultáneas concretas efectuadas por distintos grupos originarios, las que a su vez son susceptibles de ser comparadas con los siguientes objetivos: a) describir la complejidad de los entornos y las metas de trabajo de los equipos de traducción participantes en el estudio; b) conocer qué elementos conforman sus lineamientos deontológicos con fuertes implicaciones en el orden teológico; c) explorar mecanismos de gestión y resolución de desafíos traductorales; y d) orientar futuras experiencias de traducción a otras lenguas en el ámbito religioso. Bajo estos objetivos subyace el propósito general de reconocer y dignificar las lenguas-culturas originarias en su experiencia religiosa.

Con base en documentos producidos en el Encuentro de Traductores de la Biblia y la liturgia a los idiomas indígenas, ${ }^{2}$ se contras-

2 El encuentro convocado por la Conferencia del Episcopado Mexicano (CEM) se celebró en la Ciudad de México entre el 15 y el 18 de octubre de 2018. El propósito era compartir experiencias de traducción, analizar criterios de la Iglesia Católica para las traducciones bíblicas y litúrgicas, y apoyar la labor pastoral. Aunque congregó a 44 asistentes, representantes de 16 idiomas distintos, de México, Guatemala y Honduras, el programa solo contempló la presentación de las experiencias de traducción que se analizan en este reporte de investigación, a saber: los casos del tseltal, náhuatl y español de los inmigrantes en los Estados Unidos. tan prácticas de traducción activista poniendo énfasis en procedimientos de traducción manifiestos. Se presta especial atención a los criterios de traducción declarados por tres equipos que responden a las siguientes designaciones: Bachajón, ENTN (Equipo Nacional de Traductores del Náhuatl,) y BIA (Biblia para la Iglesia de América). El estudio se complementa con observación crítica en campo, entrevistas a personajes clave y estudio de documentos de primera mano procedentes de los talleres realizados por el ENTN entre 2017 y 2018.

Se ha erigido un andamiaje teórico-metodológico que busca explicitar y deconstruir el estudio de caso con base en la relación entre los estudios de traducción, la decolonialidad y la teología india y poscolonial para demostrar que se trata de prácticas de traducción activista que no solo tienen impacto en la vida religiosa de los grupos originarios participantes, sino que también contribuyen al fortalecimiento de sus lenguas-culturas. En el primer apartado explicamos por qué consideramos que nuestro caso de estudio corresponde a una traducción activista, enfatizando los fundamentos teológicos que la impulsan. E1 segundo apartado expone la composición y las metas de los equipos traductores, mientras que en el tercer apartado se presentan sus métodos, procedimientos y criterios traductorales. En particular, de sus lineamientos deontológicos derivamos síntesis ético-procedimentales relevantes para una traductología de textos religiosos. Concluimos con una síntesis de los principales hallazgos, mismos que relacionamos con las recomendaciones emanadas del encuentro mencionado. Nuestro enfoque decolonial y de teología india y poscolonial atraviesa cada una de las partes $\mathrm{y}$, aunque al final condensamos las principales conclusiones, en realidad estas van exponiéndose progresivamente. 


\section{La traducción de textos bíblicos y litúrgicos a lenguas originarias como compromiso político, social y espiritual}

Pese a que constitucionalmente México es un país de gran diversidad lingüística, con 68 agrupaciones y 364 variantes lingüísticas ${ }^{3}$ reconocidas de manera oficial, de facto vivimos un desconocimiento generalizado de ellas, aunado a una fuerte discriminación lingüística que ha impedido que se brinden servicios educativos, culturales, jurídicos y de salud, adecuados a esa variedad lingüística. El ámbito de las prácticas religiosas no ha sido ajeno a esa omisión. Por tal motivo, es preciso que la academia contribuya al fortalecimiento y la revitalización de las lenguas originarias por medio de la detección, el estudio e incluso el acompañamiento y la intervención en esos procesos sociales. En este artículo nos referiremos concretamente a un fenómeno social nacional emergente de impacto internacional que hemos observado, a saber, la necesidad de traducir textos bíblicos y litúrgicos a lenguas originarias —en particular, al tseltal y al náhuatl-, que ha motivado la creación de equipos traductores ad hoc con resultados específicos. Si bien tal necesidad aflora en el último tercio del siglo $\mathrm{xx}$, con las "comunidades de base", ${ }^{4}$ con su reclamo: "deseamos ser aceptados con nuestro rostro y corazón propios. Y ocupar el lugar que nos corresponde como hombres y mujeres verdaderas, que son hijos de Dios y de esta tierra" (López Hernández,

3 "Conjunto de variantes lingüísticas comprendidas bajo el nombre dado tradicionalmente a un pueblo indígena". Una variante lingüística es "una forma de habla que presenta diferencias estructurales y léxicas en comparación con otras variables de la misma agrupación lingüística" (INALI, 2008, p. 36).

4 Las comunidades de base son comunidades de creyentes congregadas en células más pequeñas que constituyen el sostén de la compleja y jerarquizada organización de la Iglesia Católica Apostólica Romana. s/f, p. 8), es imperante subrayar el papel cumplido de la Iglesia, al impulsar y asumir acciones tendientes a dar respuesta a tal necesidad.

Consideramos que a estos procesos detonantes de reactivación y dignificación de lenguas originarias subyace la noción de traducción de un modo ambivalente: por un lado, en cuanto "proceso específico, práctico y concreto" (Constantino, 2012, p. 131) y traducción directa a la lengua propia (Hurtado Albir, 2016, p. 57), dado que efectivamente las actividades de ambos grupos giran en torno a la traducción lingüística de textos. Sin embargo, por otra parte, dadas las tensiones generadas por el juego de fuerzas de los actores implicados en este fenómeno, conviene recordar lo señalado por la Escuela de Toledo, que presupone que el contacto no está exento de conflictos y que, a partir de la lingüística de la diferencia, una de las funciones potenciales del traductor es la posibilidad de establecer lugares de resistencia "conservando [...] el carácter dinámico de los intereses e identidades" (Carbonell, 1999, pp. 232-233). Desde nuestro punto de vista, tal concepción dota la traducción de una función activista-mediadora entre grupos jerarquizados.

Exponemos aquí la reflexión suscitada por este caso de estudio basado en las experiencias de dos equipos traductores, que nos ha llevado a establecer una incipiente relación entre teología india, decolonialidad latinoamericana y teología poscolonial desde una

metaforización de la traducción [...] para formar modelos epistemológicos y metodologías que permiten dar cuenta de lo que ocurre en [procesos] bilingües y biculturales [lo cual] indudablemente conduce a interesantes reflexiones teóricas y prácticas sobre lo que son el multilingüismo, la multiculturalidad y la interculturalidad. (Constantino, 2012, p. 132)

Ante la creciente situación de desigualdad e injusticia social sufrida por los pueblos origi- 
narios, estas prácticas vinculadas de manera muy peculiar a una de las instituciones religiosas más fuertes del planeta han desplegado distintas estrategias para lograr cambios eficaces. Por ello pensamos que es posible leerlas como "activistas". Aunque en los estudios traductológicos formales no suele hablarse de este tipo de traducción, pensamos en la traducción activista como un nuevo objeto de estudio vinculado con un proyecto político $-\mathrm{y}$, en este caso, también espiritual- porque tiene el objetivo de "encauzar de un modo u otro la energía social" latente (González Treviño, 2012, p. 29), en nuestro caso, en comunidades cristianas católicas de habla tseltal y náhuatl. ${ }^{5}$ Atestiguamos, en consecuencia, la presencia y las acciones de nuevos interlocutores y nuevas dinámicas en torno a un tema tradicional y hegemónico: el cristianismo católico que, sin embargo, presenta la novedad de ser reivindicado identitariamente. Por lo tanto, es posible afirmar que se trata de un movimiento de resistencia que persigue lógicas de comunicabilidad, inteligibilidad y traducibilidad específicas (cfr. Chow, 2008). Se trata de un campo nuevo y muy potencial para explicar procesos de comunicación intercultural.

Tales procesos inciden en la transformación (y, por lo tanto, pueden ser adjetivados como

5 Paralelamente a estas dos experiencias de traducción, en los Estados Unidos se ha generado en el nuevo milenio un fenómeno similar, con la demanda de publicación de una versión de la Biblia en español, una lengua minorizada en aquel país. Aquí exploramos también esta tercera experiencia a manera de contraste. Mientras que las dos primeras experiencias confrontan el tseltal y el náhuatl con el español como lengua hegemónica impuesta y fagocitante, en la tercera experiencia el español es desplazado por el inglés y, por lo tanto, se hace necesario reivindicarlo. El contraste es útil para ilustrar los juegos de fuerzas implicados en las políticas lingüísticas transnacionales. educativos) de las prácticas cristianas propias de las comunidades originarias, de manera que se requiere una fuerte participación de las mismas, porque el estudio de la Biblia es una experiencia muy reciente para ellas, y han "sido más receptores que sujetos activos de [su] conocimiento y manejo", por lo que se hace indispensable "que se apropien de la Biblia enmarcándola dentro de sus propios esquemas culturales" (López Hernández, s/f, pp. 2-3) mediante una postura activista. Tal postura posibilita que de "sujetos de proyectos imperialistas tales como el misionero" pasen a ser "transformadores del Cristianismo en sí, de sus instituciones políticas y eclesiásticas, de sus prácticas culturales y, por consiguiente, de su teología" (Spivak, apud Moore y Rivera, 2011, p. 6; traducción y adaptación propias).

\subsection{El compromiso político de la Iglesia Católica Romana con las lenguas-culturas originarias}

Ante más de 500 años de evangelización impuesta y avasalladora de las culturas originarias, incluso la propia matriz de la Iglesia Católica Apostólica y Romana se ha visto precisada a aquilatar, gracias a movilizaciones y presiones surgidas desde sus bases, la necesidad de dignificar a los pueblos originarios; ello coincide con la observación realizada por de Sousa Santos: el "deterioro institucional nos está llevando a una extra institucionalidad, donde los poderes dominantes de estos procesos, además de que dominan las instituciones cuando ellas no les sirven, las aprovechan y destruyen" (Santos, 2015, p. 31). Por consiguiente, se atestigua cómo desde el propio seno de la Iglesia Católica se aprovecha productiva y fructíferamente la exigencia de los pueblos indígenas en el sentido de ser reconocidos y dignificados. A este respecto, monseñor Felipe Arizmendi, obispo emérito de Chiapas, afirma: 
Hay 'luces y sombras' en el proceso de evangelización de los pueblos indígenas, ya que 'hubo frailes que defendieron la dignidad humana de los nativos, confrontándose con conquistadores y encomenderos, o defendiendo sus derechos en las Cortes y Universidades de España' y hubo religiosos que 'desconociendo el fondo de la cultura indígena, condenaron todo como diabólico’. (2019)

Entre las "sombras" o "heridas" de los pueblos originarios se encuentra el "dolor causado por el uso que se hizo de la Biblia para justificar [1a] conquista material y espiritual", que incluso ha llegado a desembocar en actos performativos, tales como la devolución de la Biblia que un grupo de indígenas peruanos hizo en 1985 al Papa Juan Pablo II "por considerarla 'instrumento de dominación' contra los pueblos a favor de los poderosos de este mundo" (López Hernández, s/f, p. 3). Paradójicamente tal reconocimiento ha llevado a la propia Iglesia a instaurar políticas y dinámicas que generen actos reparadores, tales como la dignificación de las lenguas originarias, como se explicará más adelante. Consideramos que lejos de "destruir", la Iglesia ha rearticulado su relación con los pueblos indígenas capitalizando sus saberes en armonía con una discusión teológica que se ha venido dando abiertamente desde la segunda mitad del siglo xx y que ha fructificado en la emisión de lineamientos derivados de la celebración de concilios. ${ }^{6}$

La Constitución Pastoral Gaudium et Spes sobre la Iglesia en el mundo actual (derivada del Concilio Vaticano II, 1965), por ejemplo, ad-

6 Como explica Arizmendi, no es que antes no se hubieran dado ya pasos hacia esta apertura: "Antes había ya un movimiento muy grande para estos cambios, pero lo que los oficializó fue el Concilio Vaticano II" (Comunicación personal, entrevista realizada por I. Villegas y F. Antonio, $1^{\circ}$ marzo de 2018, Teopoxco, Oaxaca, México). mite y celebra "la multiforme comunidad de los fieles" y "el patrimonio propio de cada comunidad humana", lo que por supuesto comprende las diversas lenguas. El Sacrosanctum Concilium (Constitución sobre la Sagrada Liturgia, también derivada del Concilio Vaticano II, 1963), por su parte, "respeta y promueve el genio y las cualidades peculiares de [los] distintos pueblos" y admite variaciones y adaptaciones provenientes de ellos en el rito romano. En la Congregación para el Culto Divino y la Disciplina de los Sacramentos de 1994 se señala que la diversidad, lejos de perjudicar la unidad de la Iglesia, la enriquece. En el mismo sentido, Juan Pablo II amplió el concepto de "inculturación" refiriéndose a ella no solo como el "enraizamiento del cristianismo en las diversas culturas humanas", sino previendo también "la introducción de las culturas autóctonas en la vida de la Iglesia" (Slavorum Apostoli, 1985, p. 21). Así, mientras en Aparecida (CELAM, 2007, no. 94), se señala que "es prioritario hacer traducciones católicas de la Biblia y de los textos litúrgicos a sus idiomas", se advierte también:

En algunos casos, permanece una mentalidad y una
cierta mirada de menor respeto acerca de los indí-
genas y afroamericanos. De modo que, descolonizar
las mentes, el conocimiento, recuperar la memoria
histórica, fortalecer espacios y relaciones interculturales,
son condiciones para la afirmación de la plena ciu-
dadanía de estos pueblos. (Aparecida, CELAM, 2007,
N. 96 apud Pérez Pérez, 2018, p. 225 ; el subrayado
es nuestro)

Avanzando en esta noción, el Papa Francisco se refiere a la "belleza del rostro pluriforme" de la Iglesia, y rechaza un "cristianismo monocultural y monocorde", a la vez que habla del "contenido transcultural" del Evangelio, señalando que "cada porción del Pueblo de Dios, al traducir en su vida el don de Dios, según su genio propio, da testimonio de la fe recibida y 
la enriquece con nuevas expresiones que son elocuentes" (Evangelii Gaudium, 2013). ${ }^{7}$

Es posible observar cómo con el correr de los años y en respuesta a transformaciones del orden mundial y nuevas epistemes, la Iglesia Católica ha ido asumiendo desde sus entrañas nuevas posturas hacia los pueblos originarios. Tal y como lo afirma uno de los principales exponentes de la teología india, el presbítero Eleazar López Hernández: "La Iglesia se ha ido transformando, especialmente a nivel de documentos, de principal agresora de la interioridad religiosa de los indígenas en principal aliada para su recomposición en orden a enfrentar juntos los retos de la modernidad secularizante" (s/f, p. 7). Ello se ha materializado en acciones y prácticas concretas, tales como las convocatorias de la CEM para la conformación de equipos de traductores al tseltal y al náhuatl. Por lo tanto, la CEM ha cumplido un papel agencial, con la intención y la capacidad de promover acciones (cfr. Spivak, 2017, pp. 39 y 140) desde la Iglesia Católica. El surgimiento de nuevas lógicas capaces de afrontar los argumentos de lógicas hegemónicas ${ }^{8}$ ha desembocado en acciones concretas, tales como la traducción bíblica y litúrgica a lenguas originarias, pero ya no tanto en un afán evangelizador, como el imperante durante la

\footnotetext{
7 Todas las citas y referencias de este párrafo — salvo la atribuida a Pérez Pérez- provienen del documento "Clarificación de términos", presentado por Arizmendi en el Encuentro Latinoamericano y Caribeño de Comisiones Episcopales de Liturgia sobre inculturación de la liturgia, del CELAM, celebrado en San Cristóbal de las Casas, Chiapas, México, en 2017.

8 Ejemplo de esta lógica es el recuerdo del sacerdote nahua Habacuc Hernández Vázquez, de aproximadamente sesenta años de edad, al evocar la misa en latín: "a mí todavía me tocó que el sacerdote celebraba de espalda al pueblo y cara a la pared" (Entrevista realizada por I. Villegas, 2 de marzo de 2018, Teopoxco, Oaxaca, México.
}

Conquista, sino con el fin de reforzar una identidad cristiana propia al interior de los pueblos originarios donde estos se sientan mirados, atendidos y dignificados, en pleno siglo XxI. Se trata, entonces, de una práctica de traducción activista que "tiende a romper y a disentir de los discursos dominantes [que insisten en mantener o crear] nuevas formas de monologismo uniforme y homologante" (Calefato, 2008 , p. 136) y que mira con buenos ojos un plurilingüismo que promueva la unidad católica sin dejar de aquilatar la diversidad cultural. La lengua y la inculturación son los vehículos de este reconocimiento diferenciado. En esta tarea, es loable la actividad, sobre todo, de los equipos dedicados a lenguas originarias, ante una visión homogeneizante que predominó hasta la primera mitad del siglo $\mathrm{xx}$, como admite Arizmendi: "En la misma Iglesia padecimos eso, querer uniformar. Y uniformar significaría hablando el español, haciendo las mismas celebraciones, los mismos ritos. Y eso no es católico". 9

Aun contando con justificaciones teológicas y mandatos desde el Vaticano, la incorporación al ritual romano de prácticas religioso-espirituales provenientes de los distintos grupos originarios no ha sido generalizada. Por el contrario, se han atestiguado fuertes resistencias al respecto, entre las cuales sobresalen la apatía, el desinterés y la falta de importancia otorgada al asunto por parte de muchos sacerdotes encargados de parroquias locales comunitarias. Además, no ha sido tampoco sencillo - en los casos de las parroquias que sí se han comprometido a acatar los lineamientos de inculturación y traducción emanados desde lineamientos católicos - lograr acuerdos de representatividad y participación que satisfagan a las

\footnotetext{
9 Entrevista realizada por I. Villegas y F. Antonio, 1
} marzo de 2018, Teopoxco, Oaxaca, México. 
comunidades locales. Para afrontar estas situaciones, ha sido imprescindible que cada uno de los actores implicados en el proceso tome un papel activo. Siguiendo a Carbone11: "el encuentro cultural da como resultado solapamientos y negociaciones entre grupos opuestos. La actuación o agencia se da en ambos lados" (1999, p. 233, subrayado original). Aun cuando se insiste en demasía en la sana doctrina católica, de alguna manera, se cimbra la liturgia tradicional romana y algunos preceptos de religiosidad local logran trasminar el corpus de prácticas católicas; podríamos afirmar, entonces, que se "desestabiliza" en cierta forma, la cultura de llegada (Carbonell, 1999, p. 234) y, en definitiva, entendemos esta práctica como traducción activista que puede incidir en la transformación del orden preponderante. La capacidad performativa del traductor, su actuación o agencia, puede ser usada en ambos sentidos: para repetir acciones colonizadoras, para perpetuarlas o para desestabilizarlas. Desestabilización y agencia parecen ser, por lo tanto, dos nociones sociopolíticas que se ligan a la traducción cultural. Sostenemos que, en cuanto noción, la traducción subversiva como un proceso de descolonización (Carbonell, 1999, p. 236) puede ejemplificarse en las prácticas que nos ocupan. En nuestro caso de estudio, la figura del traductor poscolonialista destaca porque se realizan propuestas editoriales y de estilo de transmisión del Evangelio al detectar qué y cómo debe ser traducido, contribuyendo así a la labor de diseminación cultural de la Biblia y la liturgia católica con una conciencia clara sobre las voces periféricas que requieren ser oídas en diferentes escenarios glocales.

Al tratar de explicar la compleja relación entre los distintos actores que conforman las prácticas de traducción que nos ocupan, recurrimos al topos de la "traducción intercultural" (Santos, 2006) para hacer énfasis en la necesidad de reconocer el carácter persistentemente colonial de las relaciones interculturales contemporáneas y para desarrollar desde este reconocimiento una capacidad de enlazar diversos saberes históricamente subalternizados, invisibilizados y discriminados con el canon occidental del "saber", a menudo impuesto desde tiempos coloniales como el único legítimo. Como consecuencia, una pedagogía decolonial, como la que propone Walsh (2013) es aquella que recupera el legado histórico de las luchas anticoloniales y liberadoras para traducir saberes desde lo propio hacia lo ajeno, desde lo comunitario y local hacia lo societal y extralocal. La resultante "ecología de saberes" (Santos, 2006) consiste en traducir entre diferentes saberes, pero a la vez, asimismo, entre diferentes prácticas y actores: "La traducción es un proceso intercultural, intersocial. Utilizamos una metáfora transgresora de la traducción lingüística: es traducir saberes en otros saberes, traducir prácticas y sujetos de unos a otros, es buscar inteligibilidad sin 'canibalización', sin homogeneización" (Santos, 2006, p. 32). Aplicada a los saberes relativos al sentipensar y la fe de nuestros pueblos originarios, esta perspectiva decolonial latinoamericana puede resumirse en una sentencia sencilla, pero profunda: "Hablarle de Dios en su idioma, es un derecho de [los] pueblos". ${ }^{10}$

La traducción entendida en este sentido amplio es, a la vez, un acto educativo transformador: dota a los actores de saberes nuevos y simultáneamente genera capacidades de enlazar distintas fuentes y tipos de saberes - presentes, emergentes, ausentes- en su agenda política como movimiento social. El enfoque intercultural que recupera, visibiliza e imbrica diversos saberes, adopta así un enfoque inter-

10 Comunicación personal, $1 .^{\circ}$ de marzo de 2018, Teopoxco, Oaxaca, México. 
actoral, que enlaza a los propios sabedores y que, en nuestro caso, permite dar cuenta de procesos educativos transformadores al interior de cada uno de los equipos traductores que estudiamos; el impacto producido no se queda resguardado dentro de ellos, sino que repercute en el entramado más amplio de la organización de la Iglesia Católica, y posibilita experiencias de otros grupos originarios en la traducción a sus lenguas.

\section{Los equipos de traducción}

Los tres equipos de traducción que nos ocupan tienen el común denominador de haber surgido a partir de la iniciativa de algún órgano superior de la Iglesia Católica local, razón por la cual subrayamos el carácter agencial de las instancias de autoridad con posibilidad de convocatoria, tales como la CEM y la Conferencia Episcopal de los Estados Unidos para los inmigrantes hispanoparlantes (USCCB), quien a su vez hizo el encargo al Consejo Episcopal Latinoamericano (CELAM). Se trata de grupos de distinto origen, composición, fuerza de cohesión y alcance. Procedemos a describirlos brevemente, subrayando su carácter comunitario, eclesiástico-ejecutivo o bien mixto, lo cual refleja sus capacidades organizativas y de producción textual. Si bien las instancias convocantes gozan de potestad, ello no quita que todos los actores implicados en el proceso ejerzan su agencialidad con implicaciones para los resultados. Es menester enfatizar que el motor de estos equipos no es la ausencia de versiones bíblicas en náhuatl, tseltal o español, pues ya existían antes de iniciar estos procesos; se trata de una necesidad específica de producir y sentirse reconocidos en una versión propia que contemple aspectos de lengua-cultura relevantes para estos grupos originarios. En el caso de las lenguas originarias persiste la idea de que las versiones existentes, derivadas en muchos casos de esfuerzos de las iglesias evangélicas, ${ }^{11}$ ignoran o no contemplan en su justa medida la dimensión sociocultural y, sobre todo, la confesión de fe de los grupos étnicos a los que van dirigidas. Obsérvese la opinión al respecto de un personaje clave en el impulso de las traducciones litúrgicas y bíblicas a las lenguas originarias en México, Monseñor Arizmendi:

Yo les hacía a los sacerdotes, catequistas y diáconos esta observación: tenemos varias traducciones evangélicas, sobre todo de las Sociedades Bíblicas Unidas, para el tseltal, tsotsil, ch'ol, tojolabal, y no hay ninguna católica. Eso es una vergüenza. Eso es una infidelidad a los pueblos. ${ }^{12}$ Tenemos que subsanar esa deficiencia. Y reitero: nos dimos a la tarea de lograr estas traducciones. Mi antecesor, Monseñor Samuel Ruiz García, empezó este trabajo, aunque sin darle todavía la formalidad de una traducción oficial. Se empezaron a hacer experiencias. Él trabajó muchísimo en la dignificación de los indígenas, en defender sus derechos, sobre todo, su derecho a ser personas. Y uno de estos derechos es el uso de la lengua, del idioma propio, que es lo que da identidad. Empezamos a formar equipos de traductores de cada idioma, con las diferentes parroquias. ${ }^{13}$

Desde nuestro punto de vista, entre los principales impulsos para participar en nuevas

11 Valga el reconocimiento que algunos católicos de la talla de López Hernández realizan respecto a estos esfuerzos:

las iglesias protestantes han tomado la delantera a la Iglesia Católica Romana haciendo traducciones en buena cantidad de las lenguas autóctonas de América. Hace apenas unos veinte años la Iglesia Católica empezó a hacer traducciones de toda la Biblia con gente indígena y, a veces, lo han hecho de manera ecuménica o con apoyo de las Sociedades Bíblicas Unidas. (s/f, pp. 2-3)

12 En otra parte, Arizmendi afirma contundente: "Es una pena, una vergüenza, una injusticia, que hasta ahora el pueblo náhuatl no tenga una Biblia católica, aprobada por la Conferencia Episcopal. [...] Que el Señor nos perdone este grave pecado de omisión” (2016, p. 30).

13 Comunicación personal, $1^{\circ}$ de marzo de 2018, Teopoxco, Oaxaca, México. 
versiones de la Biblia en estas lenguas se encuentran: a) sentirse reconocidos, consultados e implicados en el proceso de traducción, y b) lograr versiones incluyentes y atentas a los componentes lingüísticos y socioculturales de los grupos originarios. Estos impulsos derivan en un empoderamiento de los grupos comunitarios base de feligreses, así como en un enriquecimiento de las Escrituras, el misal y el rito romano de la Iglesia Católica. Cada equipo ha instaurado su propio ritmo de trabajo, que consiste en el desempeño de ciertas labores en grupos pequeños, los cuales luego se reúnen en células más amplias o incluso plenarias.

\subsection{Bachajón (tseltal)}

Ubicada al noreste del estado de Chiapas, en el municipio de Chilón, la Misión de Bachajón, perteneciente a la Diócesis de San Cristóbal de las Casas, inició en 1969 la traducción bíblica y litúrgica al tseltal, lengua mayense, la segunda más hablada en Chiapas, después del español, con alrededor de 461236 hablantes de acuerdo con el censo 2010, lo cual la convierte en la quinta lengua más hablada en México (INEGI, 2010). Mientras que el 58\% de la población estatal declara su confesión católica (frente al 83\% a nivel nacional, INEGI, 2010), se calcula que en Bachajón hay alrededor de 4 mil habitantes que, en su mayoría, hablan tanto tseltal como español, (Nuestro México, 2011). El tseltal pertenece a la familia lingüística maya; el Catálogo de lenguas del Instituto Nacional de Lenguas Indígenas (2008) contempla las variantes de occidente, norte, oriente y sur, enmarcando la de Bachajón en el norte.

Convocado por la CEM, en un lapso de 25 años logró conservarse un equipo base de traductores, entre quienes se encuentran feligreses de la comunidad, sacerdotes indígenas y no indígenas y personal eclesiástico, que ha ido renovándose al tiempo que ha ido integrando nuevas metodologías acordes con sus necesidades y aprendizajes, hasta lograr, en 2005 la publicación en tseltal de la Biblia completa y, en un proceso paralelo, en 2006, la aprobación de la traducción del Ordinario de la misa. A la fecha, se cuenta con la Biblia en tseltal, así como con el Misal romano traducido a lengua tseltal (texto bilingüe español-tseltal) publicado en tres tomos por la CEM. ${ }^{14}$. Su avance es, por lo tanto, muy notorio.

\subsection{El Equipo Nacional de Traductores del Náhuatl (ENTN)}

Este equipo surgido en 2012 tiene como tarea principal la traducción litúrgica de textos católicos. Incluye a nahuablantes de regiones representativas de nuestro país y, por lo tanto, distintas variantes de esta lengua mayoritaria (que cuenta con 1725620 hablantes, de acuerdo con el censo 2015, repartidos en por lo menos 16 estados de la República, http://cuentame.inegi.org.mx/hipertexto/todas_lenguas. htm). El catálogo del INALI reconoce veinte variantes geográficas del náhuatl, perteneciente a la familia yuto-nahua. El ENTN está conformado por un total de alrededor de 36 integrantes (cifra oscilante), entre quienes se encuentran nahuablantes (ya sea porque es su lengua

14 No omitimos mencionar otras lenguas mayenses a las que ha sido traducido, bajo esta misma lógica, por lo menos el Nuevo Testamento. Sin embargo, quedan fuera de este artículo dado que no hubo presentaciones al respecto en el Encuentro de Traductores que nutre nuestras fuentes documentales. Una primera edición de la Biblia en tsotsil para habitantes de Chenalhó, realizada por las Sociedades Bíblicas Unidas y la Diócesis de San Cristóbal vio la luz en 1998, cuando don Samuel Ruiz era obispo de Chiapas. En 2008 se realizó la segunda edición (Martín Pérez, 2015). Por otra parte, la CEM aprobó también el NT en tsotsil de Huixtán y la Biblia en tsotsil de Zinacantán, en Chiapas (Arizmendi, comunicación personal, 29 abril 2019). 
materna o porque la han aprendido), que son presbíteros de distintas diócesis, religioso/as, diáconos, laico/as, representantes de la CEM y asesores invitados provenientes de las siguientes entidades: Ciudad de México (mexicano del centro alto), Hidalgo (Huautla, Huejutla y Tulancingo, mexicano de la Huasteca hidalguense; Hueyapan, náhuatl de la sierra oeste de Puebla), Morelos (Hueyapan, mexicano de Tetela del Volcán), Nayarit (el Nayar, mexicano alto de Occidente), Oaxaca (Teopoxco, náhuatl de Oaxaca), Puebla (Tehuacán, náhuatl de la sierra norte), San Luis Potosí (Ciudad Valles, náhuatl de la Huasteca potosina), Tlaxcala (Tlaxcala, náhuatl de la Huasteca potosina) y Veracruz (Orizaba, mexicano central de Veracruz; Pajapan, náhuatl del Istmo; Tuxpan, mexicano de la Huasteca veracruzana). El ENTN contempla, por consiguiente, 11 de las 20 variantes reconocidas en el Catálogo del INALI. Hay también miembros del equipo que no son nahuablantes. Es significativo resaltar que existe una intención deliberada por parte de los organizadores del Taller, de realizar sus actividades en pleno corazón de alguna comunidad originaria preferentemente nahuahablante, salvo la emisión correspondiente al mes de octubre, que se realiza en la Ciudad de México, sede de la Basílica de Guadalupe, donde tiene lugar la misa en náhuatl coincidente con la conmemoración del Encuentro entre España y América, es decir, poniendo énfasis en la diversidad cultural e intentando sobreponer tal conmemoración a la del Día de la Raza, sobre todo, porque la Virgen de Guadalupe, a quien está consagrada dicha Basílica, eligió la lengua náhuatl para revelarse en el Tepeyac (Siller Acuña, s/f).

Así pues, la realización de cuatro misas anuales completamente en náhuatl es un hecho de gran trascendencia político-espiritual para los pueblos nahuas si se toma en cuenta lo sostenido por López Hernández: "nuestra evan- gelización fue más mariana que cristológica" (s/f, p. 6). Se trata, entonces de una "teología contextual y política" tal y como la enmarcan los estudios en teología poscolonial (Moore y Rivera, 2011, p. 4; traducción propia), ya que el náhuatl es el idioma "que quiso usar la Virgen de Guadalupe en sus diálogos con Juan Diego. No era el que ella sabía y usaba en Nazaret [recuérdese que la Virgen de Guadalupe es una de las manifestaciones de la Virgen María], el arameo, sino el de su interlocutor. No le impone el idioma de los conquistadores." (Arizmendi, 2016, p. 29). Como tal, la teología poscolonial surge como "un sitio de intensa energía política e intelectual fuertemente marcada por una preocupación sin precedentes por los efectos de los imperialismos -tanto antiguos como nuevos-" (Moore y Rivera, 2011, p. 4; traducción propia). Es muy importante señalar que, aunque entre los planes del ENTN se encuentra la traducción de la Biblia, aún no se llega a ese punto; hasta ahora solo se han realizado traducciones de textos litúrgicos.

\subsection{BIA (español en los Estados Unidos)}

La razón que puso en marcha a este equipo fue contar con una "Biblia en español para los inmigrantes hispanos [...] hecha por y para hispanohablantes de toda América" (BIA, 2015). De acuerdo con el Censo de población publicado en 2015 por el gobierno de los Estados Unidos, elaborado con base en información recabada entre 2009 y 2013, el número total de hablantes con cinco años de edad o más asciende a 291.484.482, de los cuales 60.361 .574 (es decir, el 20,7\%) hablan en casa algún otro idioma además del inglés. Entre estos, 37.458 .470 (esto es, el 12,8\% con respecto al universo total de hablantes y $62 \%$ en relación con el universo de quienes hablan otra lengua además del inglés) son hablantes de español. Estas cifras revelan que, pese a que 
el español ocupa el primer lugar entre las lenguas distintas al inglés, esta es una lengua minorizada si se contempla el total de hablantes considerados en el censo en ese país.

Originado en los Estados Unidos y habiendo delegado su misión al CELAM (cuya sede se encuentra en Bogotá, Colombia), el equipo de traducción BIA se conformó en 2004; se ha caracterizado por ser multinacional e incluir en su núcleo a jerarcas de la Iglesia Católica Latinoamericana tales como obispos de Chile y Argentina, así como a presbíteros de Colombia, México, Centroamérica, Caribe y Cono Sur, además de clérigos de Estados Unidos. Como puede apreciarse, este grupo está integrado exclusivamente por sacerdotes con altas responsabilidades eclesiales y es factible asegurar que han tenido el privilegio de una larga trayectoria educativa. El equipo ampliado se extiende a 26 traductores especializados en textos bíblicos (cfr. BIA, 2015) que han trabajado entre 2005 y 2015. Su propósito —aún en curso- es conseguir una Biblia dirigida a los hispanohablantes no solo de los Estados Unidos, sino de toda América Latina; de ahí su alcance continental, logrando la traducción íntegra del Nuevo Testamento desde el griego con introducciones, notas, mapas, cronología y glosario bíblico que se publicó en 2015 con la autorización de las conferencias episcopales de 22 países latinoamericanos y del Caribe. Es importante señalar que la consideración de una variante adecuada para América Latina es de gran peso no solo lingüístico, sino también teológico, ya que, como afirma Arizmendi:

Afortunadamente hace más de 50 años inició el movimiento en la Iglesia de hacer las celebraciones en los idiomas propios. Fue todo un proceso: al principio solo las lecturas de la biblia, los saludos; después las oraciones; lo último fueron las fórmulas fundamentales de los sacramentos. Incluso un tiempo teníamos una sola traducción en español, única para toda América Latina y España, porque no se permitía más que un solo español. Pero con el tiempo, no. Ya hay traducciones diversas del español, según las regiones de nuestra América Latina, distintas a la de España. ${ }^{15}$

\section{Elementos manifiestos que conforman las prácticas de traducción de los equipos}

A partir de las presentaciones realizadas por los tres equipos en el Encuentro de Traductores de la Biblia y la Liturgia a los Idiomas Indígenas, pudimos detectar que cada equipo ha implementado y plasmado en algún documento metanarrativo un modo particular de realizar sus traducciones. Mientras el equipo Bachajón lo denomina metodología, el ENTN lo llama un caminar, y bia, procedimiento. Nos referimos aquí a los elementos manifestados por los equipos aunque seguramente existen aspectos no incluidos en las metanarrativas susceptibles de ser observados en investigaciones futuras; sin embargo, el hecho de que estos sean los incluidos en sus autodescripciones es relevante por su valor ontológico y epistemólogico, lo cual constituye un claro ejemplo de lo que Mignolo (1996 y 2009) denomina "epistemología del Sur", esto es, visiones de trabajo que no persiguen la imitación ni siguen modelos impuestos sino que, antes bien, contemplan prácticas propias. En los dos primeros equipos es muy importante la participación de las comunidades de base y se logran avances colectivos. En el tercer equipo se privilegia la participación de especialistas con alta formación académica en teología. Consideramos que los tres equipos tuvieron la libertad de elegir el rumbo y la manera de cumplir la misión para la cual fueron creados; ello nos permite calificar, siguiendo a Spivak (apud Moore y Rivera, 2011, p. 110; traducción propia), a la CEM y a la USCCB como actores guiados por un "enfoque multiculturalmente sensible a

15 Comunicación personal, $1 .^{\circ}$ marzo de 2018, Teopoxco, Oaxaca, México. 
la generación o la recuperación de información [en contraste con la habitual] mímesis apropiadora o imitación transcultural" meramente extractivista.

El equipo Bachajón contempla cuatro fases amplias en su metodología (Figura 1), que califican como traducción dinámica, a saber: traducción base, transcripción, revisión y publicación. La primera consiste en que algún miembro hablante originario del equipo traduzca al tseltal directamente del español. Resalta la importancia que se le da a la transcripción pues, por una parte, devela la dificultad de escribir una lengua de fuerte oralidad que muchos hablantes están aprendiendo a escribir y, por la otra, da cuenta de cómo en los primeros años de trabajo del equipo, esta labor se efectuaba en máquina de escribir para después hacerlo en computadora con procesadores de textos. Por consiguiente, hay un proceso colectivo y paulatino de adquisición de habilidades para la escritura del tseltal, así como para el manejo de herramientas de escritura. Tales habilidades van de la mano con literacidades específicas que no se limitan a la traducción, sino que implican también diversos aprendizajes que han sido favorecidos por la participación en el equipo.

El rubro revisión implica la revisión pastoral realizada por las comunidades a través del leccionario dominical o bien por parejas conformadas por algún matrimonio o padre-hija; la perspectiva de género considerada en esta fase es peculiar y única de este equipo. Posteriormente se valida con la comunidad. La revisión final es efectuada por un miembro del equipo de traductores más un miembro del equipo misionero, no necesariamente hablante originario del tseltal, pero sí experto en cuestiones bíblicas, litúrgicas o teológicas. El equipo señala la utilización de las exége- sis de Schoekel, de la BAC ${ }^{16}$ y otros autores (no mencionan cuáles), y las notas de la Biblia de Jerusalén. En esta fase de revisión, el equipo misionero sí confronta con los textos griego y hebreo, apoyados en la versión interlineal griego-español, y cuenta con la ayuda de expertos en la materia para las palabras clave. La revisión bíblica va acompañada de una revisión lingüística, en la que un miembro del equipo de traductores de lengua materna tseltal procura un estilo literario uniforme y una sintaxis tseltalizada, teniendo siempre a la vista el texto en español. El último paso seguido por el equipo es la aprobación eclesial a cargo de las comisiones episcopales de Doctrina de la Fe, Cultura, Pastoral Bíblica y Liturgia para luego pasar al pleno de la CEM para su aprobación definitiva. El proceso culmina con la entrega del texto requisitado para su publicación.

E1 ENTN sigue un caminar que oscila entre lo realizado en las comunidades de base (parroquias), los talleres - que cuentan con carácter de asamblea, donde se toman decisiones consensuadas sobre las opciones de traducción y la versión final, la comunicación con autoridades eclesiásticas y la aplicación de la versión obtenida en las comunidades, como puede observarse en la Figura 2. Al igual que el equipo traductor al tseltal, el ENTN da un fuerte peso a la aprobación o aceptación comunitaria de los textos. Cabe subrayar que cuenta con un Consejo Asesor conformado por entre seis y ocho miembros del Equipo, en su mayoría sacerdotes más expertos en asuntos sociolingüísticos, que llevan a cabo una revisión meticulosa de los textos finales, esta fase de la revisión coincide, por lo tanto, con la implicación de misioneros expertos en la revisión textual que efectúa el equipo Bachajón.

16 Con BAC, el equipo Bachajón se refiere coloquialmente a la Lingüistica y exégesis bíblica, de Santiago García-Jalón, de la Biblioteca de Autores Cristianos (de la Conferencia Episcopal Española), 2011, col. Estudios y ensayos, 324 pp. 


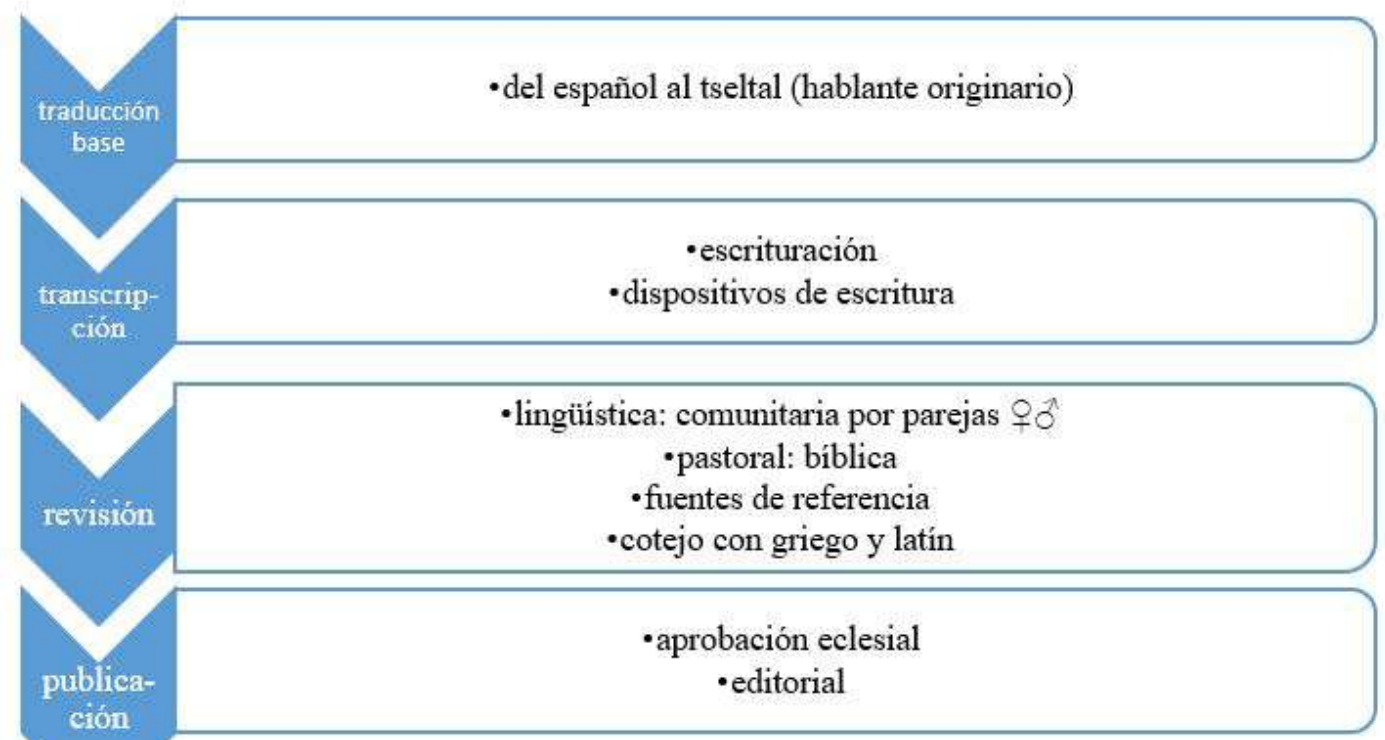

Figura 1 Metodología Bachajón. Elaboración: Villegas (2019)

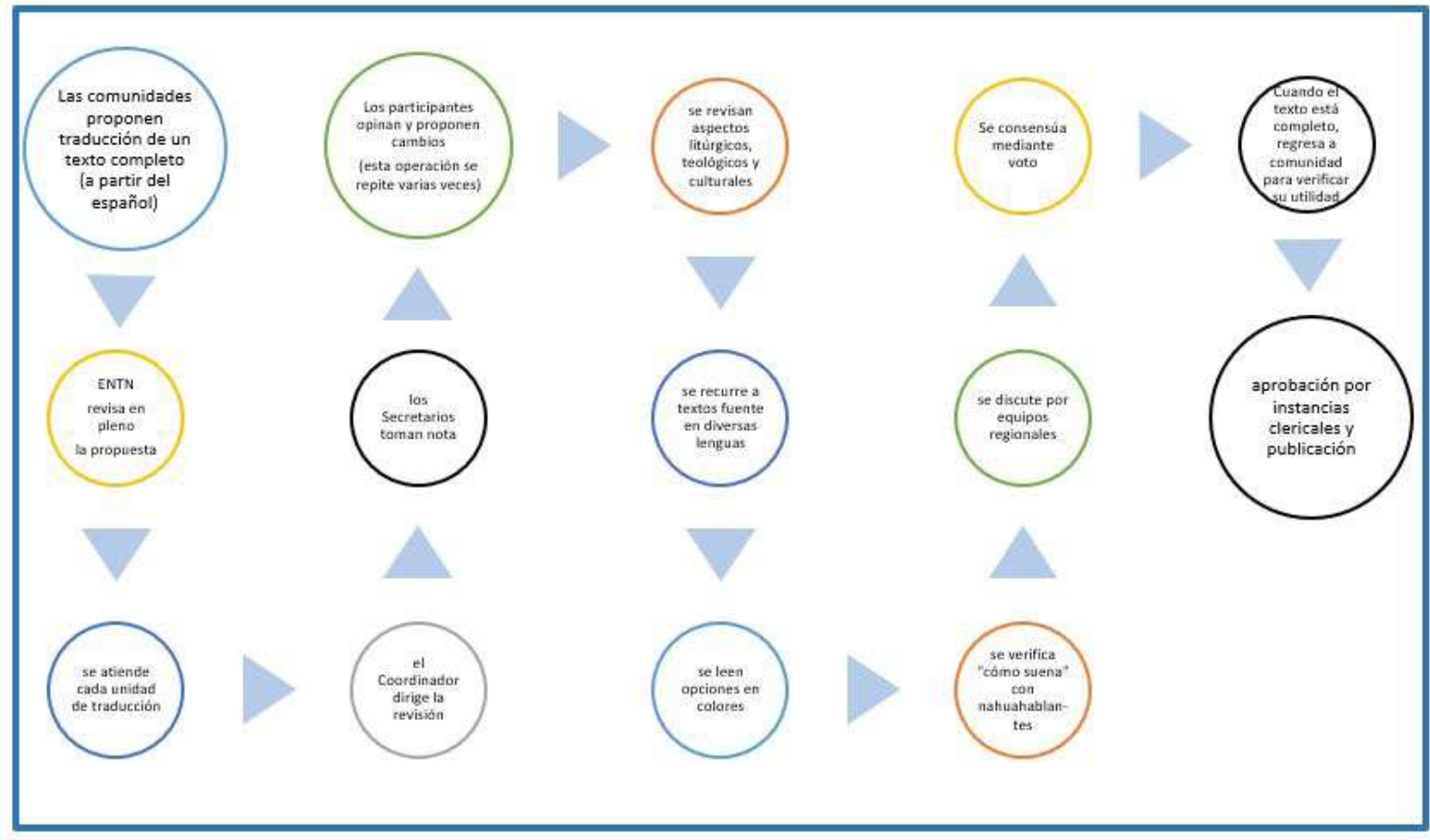

Figura 2 El caminar del ENTN. Dinámica de trabajo. Elaboración: Villegas (2019)

Criterios de traducción bíblica-litúrgica al tseltal, al náhuatl y al español minorizado:

un paradigma de traducción activista 
Por su parte, BIA contempla en su procedimiento tres grandes fases, a saber: análisis, transferencia y emisión (Figura 3). En la primera fase se identifican problemas textuales y se realiza una distinción entre estructuras literarias de superficie (palabras y elementos de la oración tal y como se dicen y pronuncian) y profundas (palabras y elementos estructurados gramaticalmente poniendo atención a la ambigüedad). Esta descripción devela la adhesión al pensamiento de Chomsky erigido en torno a la gramática generativa transformacional. La segunda fase implica la elaboración de campos semánticos de significados nucleares propios de la lengua fuente y receptora que permitan captar matices de un mismo término en la obra para reformular en lengua receptora los sintagmas análogos a la lengua fuente para la comprensión del sentido. Es muy importante que la traducción se realiza a partir de las lenguas originales en que fue producida la Biblia (arameo, hebreo y griego), a diferencia de los otros equipos cuya base es la versión en español. Además, se respeta el vocabulario bíblico consolidado, es decir, se atiende a la tradición. La tercera fase, emisión, se preocupa por reproducir con belleza el estilo literario de la lengua fuente mediante recursos pertinentes en la lengua de recepción; se pone mucho énfasis en que el resultado sea exacto y que se comprenda con facilidad, para lo cual se presta atención a problemas textuales, exegéticos y lingüísticos, así como a los anacronismos, para lograr una modernización a esto se le llama "texto adaptado". El texto resultante se usa en teología, liturgia y evangelización. A diferencia de los otros dos equipos, en este prevalece una explicación procedimental de fuerte raigambre teórica expresada mediante un argot especializado.

\section{análisis \\ oproblemas textuales \\ - estructuras de superficie y profundas}

\section{transferencia}

- campos semánticos de significados nucleares en LF y LR

- traducción a partír de arameo, hebreo y griego

- vocabulario bíblico consolidado

\section{emisión (texto adaptado)}

- estilo literario LF-LR

- problemas textuales, exegéticos y lingüisticos

canacronismos

Figura 3 Procedimiento BIA. Elaboración: Villegas (2019) 
Si bien comprendemos la necesidad expresa de los tres equipos de incluir a expertos en Biblia y liturgia a fin de actuar en armonía institucional, coincidimos con López Hernández en subrayar cierta "desconfianza" por parte del clericalismo oficial hacia los actores indígenas y sus lenguas-culturas y calificarla como uno de los "resabios del colonialismo" (s/f, p. 3) que es menester superar mediante una postura activista a fin de "crear formas nuevas y adecuadas de transmisión [...] a fin de que alcancemos un nuevo encuentro más gozoso y enriquecedor de los pueblos con la Biblia [y la liturgia]" (ibid). Es necesario, por lo tanto, que pasen de ser "copilotos del avión" a pilotos principales (ibid).

Destaca, asimismo, la participación comunitaria prevista en los equipos que trabajan con lenguas autóctonas puesto que en la traducción activista es preponderante que "se diga la verdad, lo que la gente tiene en su corazón realmente. Que tengan derecho a ser, dentro de la Iglesia, como son, ¿no?" (Entrevista al presbítero Pérez Pérez). Resulta notorio que tal participación queda ausente en el tercer equipo, conformada únicamente por especialistas y en cuyos procedimientos no se prevé la intervención de un grupo de receptores para fines de aprobación o comprobación de la eficacia textual, si bien está contemplado para la generación de la traducción en sí.

\subsection{Criterios de traducción de los equipos}

Cada uno de los equipos ha ido esbozando, con el correr de los años de su práctica, esto es, con un profundo sentido experiencial o emic, que aporta la mirada, la experiencia y el sentir de los propios actores, un conjunto de criterios que les va permitiendo autoidentificarse de manera colectiva y que cumplen una doble función: por un lado, representan un férreo anclaje a un deber ser $-\mathrm{y}$, por lo tanto, pasan de ser emic a ser etic, de ser actores y protagonistas a ser igualmente sus propios observadores autoconscientes y autocríticos - mientras que, por otra parte, fungen como la clave de acceso y permanencia para potenciales nuevos miembros. Esta doble postura marca la autoconciencia de la necesidad de proseguir con la tarea en el futuro caracterizándose en lo que cada uno considera imprescindible. Pensamos que tal elaboración — de por sí compleja porque implica un autoexplicarse interno y un demostrarse a otros externamente- - puede ser esclarecido en términos de lo que Spivak denomina una "teología política" porque implica "aprender a autorrepresentarse ante el Otro", en un juego de relaciones donde tanto las entidades convocantes como los equipos rechazan categorías de representación impuestas a priori y evitan conscientemente caer en generalidades que "harían peligrar la integridad [de cada equipo] particular" (apud, Moore y Rivera, 2011, p. 296; traducción propia).

El equipo Bachajón contempla solamente siete criterios para apegarse a su método de traducción dinámica, que evidentemente hace referencia a Nida (en Venuti, 2006) y que se basa en "el principio del efecto equivalente", es decir, se busca que la relación entre el receptor y el mensaje sea sustancialmente la misma que existe entre los receptores y el mensaje originales. Así pues, se insiste en la naturalidad de la expresión y se hace el esfuerzo por relacionar al receptor del texto meta con formas de comportamiento relevantes en el contexto de su propia cultura a fin de que "la Palabra de Dios se exprese en tseltal" (primer criterio). Se estipula cuál es el texto base para la traducción y cuál es la variedad a la que se traduce (segundo y tercer criterios), quiénes son los traductores y qué papel cumplen los misioneros, es decir, los actores que deben intervenir en el proceso (cuarto criterio), las normas ortográficas comunes (quinto crite- 
rio), la creación de un diccionario de términos bíblico teológicos con asesoría de biblistas y lingüistas expertos en tseltal (sexto criterio) y la recomendación de no tomar préstamos del español, pero sí de otras variantes del tseltal (séptimo criterio) (Tabla 1).

El ENTN cuenta con dos tipos de criterios: una lista de 13 "criterios de traducción" y otra conformada por 32 "criterios traductológicos" (en Hasler, Antonio y Martínez, 2017). El primer listado guarda cierto parecido con los criterios de Bachajón, ya que también se refiere a grafías acordadas (primer criterio), pone énfasis en que los términos y conceptos sean los adecuados al texto litúrgico (segundo), y determina que la traducción propuesta sea aprobada en asamblea (tercero), mantiene actitud de apertura en la revisión colectiva poniendo atención a los memoriales para seguir los acuerdos de asamblea (quinto) y, en este mismo punto se hace referencia, como en Bachajón, a la generación paulatina de un glosario. $\mathrm{Al}$ igual que el equipo anterior, se contempla recurrir a obras de referencia necesarias (sexto), así como tener presentes aspectos bíblicos, litúrgicos, teológicos, socioantropológicos, lingüísticos, traductológicos y pastorales (séptimo), subrayando un documento específico: los Criterios de traducción de la Congregación para el Culto Divino y la Disciplina de los Sacramentos, Varietates Legitimae sobre la liturgia romana y la inculturación (1994) (octavo) (Tabla 1).

El cuarto criterio contrasta con Bachajón en que recurre a otras variantes del náhuatl pero, a diferencia de aquel equipo, la tendencia es "evitar que prevalezca una [sola] variante", mientras que los criterios noveno y décimo hacen recordar que la lengua náhuatl es aglutinante y reverencial y es una lengua dinámi$\mathrm{ca}$, que se revitaliza y actualiza. Otra notoria diferencia radica en que el punto once prevé abiertamente que se dé una catequesis litúrgica sobre términos y conceptos a los receptores de las traducciones, prevé el proceso de ida y devolución entre comunidades y asamblea para proponer, aplicar y corregir las traducciones (doceavo), así como acudir a las distintas comisiones de la CEM a fin de obtener credibilidad y legitimidad. Son criterios manifiestos por Bachajón y ENTN.

Los 32 principios contenidos en los criterios traductológicos del ENTN parten del precepto general de Sapir (1954, pp. 30-31) de que todo lo que se puede pensar y decir en una lengua puede pensarse y decirse en otra. Se trata de criterios ortográficos y referentes a las distintas partículas aglutinantes del náhuatl, a indicadores de número, formas diminutivas y reverenciales y otros aspectos lingüísticos muy específicos, que tienden hacia una normalización del náhuatl, en el entendido de que se trata de una función especial de la lengua por su carácter litúrgico. En particular, los criterios diez a tres son de interés porque prevén variantes dialectales, pero señalan criterios ortográficos fijos y que debe darse preferencia a los dialectos más extendidos. Los criterios catorce a quince ponen énfasis en que "no todo lo que se pronuncia se escribe" así como en que cada hablante cuenta con una "gramática mental" de la que puede echar mano, de tal suerte que también abona a la normalización e incide en los procesos formativos autonómicos emparentados con literacidades nuevas para los hablantes del náhuatl.

Consideramos que este esfuerzo es crucial en las distintas luchas que se están dando en distintos ámbitos - como el académico (universidades interculturales que aspiran a normalizar las lenguas originarias como lenguas de comunicación académica, cfr. Dietz y Mateos Cortés, 2019) o el escolar (iniciativas para incluir prácticas sociales del lenguaje en un cu- 
Tabla 1 Criterios de traducción de los equipos Bachajón, ENTN y BIA, sintetizados y agrupados por descriptores de elementos éticos y metodológicos

\begin{tabular}{|c|c|c|}
\hline Tipo de descriptor & Descriptor & Equipo \\
\hline \multirow{4}{*}{$\begin{array}{l}\text { Teórico- } \\
\text { metodológico }\end{array}$} & Equivalencia dinámica (Nida) & Bachajón y ENTN (implícito) \\
\hline & gramática generativa transformacional (Chomsky) & $\mathrm{BIA}$ \\
\hline & adaptación a la época y vocabulario accesible & \\
\hline & creación de lengua especializada o litúrgica & ENTN \\
\hline \multirow[t]{8}{*}{ Metodológico } & tf: español / tm: lengua originaria & Bachajón y ENTN \\
\hline & tf: arameo, hebreo y griego / español & $\mathrm{BIA}$ \\
\hline & variante única (préstamos en caso necesario) & Bachajón \\
\hline & todas las variantes para propiciar la comprensión & ENTN \\
\hline & normas ortográficas y morfológicas comunes & Los tres \\
\hline & glosarios & \\
\hline & prólogos, notas & $\mathrm{BIA}$ \\
\hline & manual para uso de preposiciones & ENTN \\
\hline \multirow[t]{2}{*}{ Contenidos } & $\begin{array}{l}\text { bíblicos, litúrgicos, teológicos, socioantropológicos, lingüísticos, } \\
\text { traductológicos, pastorales }\end{array}$ & Los tres \\
\hline & estilísticos (géneros, matices, figuras retóricas) & \\
\hline \multirow[t]{8}{*}{ Deontológico } & expresión de la Palabra de Dios en lengua propia & \multirow[t]{2}{*}{ Los tres } \\
\hline & aprobación oficial de instancias superiores & \\
\hline & catequesis & ENTN \\
\hline & apego a Varietates Legitimae & \\
\hline & énfasis en la tradición magisterial & $\mathrm{BIA}$ \\
\hline & manejo y resguardo bíblico exclusivo de la ecclesia docens & \\
\hline & $\begin{array}{l}\text { confianza del manejo y resguardo bíblico supervisado a la } \\
\text { ecclesia audiens }\end{array}$ & Bachajón y ENTN \\
\hline & tseltalizar, nahuatlizar (lingüística y teológicamente) & \\
\hline \multirow[t]{6}{*}{ Actoral } & traductores originarios para traducción lingüística & \\
\hline & clérigos o misioneros para revisión de contenidos & \multirow[t]{3}{*}{ Bachajón y ENTN } \\
\hline & asesoría de miembros externos & \\
\hline & se prevé necesidad de formación de traductores comunitarios & \\
\hline & $\begin{array}{l}\text { exclusivamente clérigos altamente especializados para todo } \\
\text { el proceso }\end{array}$ & $\mathrm{BIA}$ \\
\hline & señalamiento de altas competencias deseables del traductor & \\
\hline
\end{tabular}

Elaboración: Villegas (2019)

rrículum intercultural y bilingüe para la educación básica, cfr. Olarte, 2010)—, por lograr estandarización escrituraria de esta lengua. A este respecto, Moreno Cabrera afirma:

Una comunidad lingüística en la que hay diversas variedades idiomáticas puede tener la necesidad de crear un estándar [...] Estos estándares pueden po- sibilitar que los miembros de las diversas comunidades en las que se hablan distintas variedades se sientan miembros de una comunidad más amplia que luche conjuntamente por la preservación y potenciación de sus lenguas comunitarias. En determinadas situaciones sociopolíticas, el carecer de una variedad estándar puede poner en peligro la supervivencia de una o varias lenguas. [...] ese estándar no es ni mejor ni más auténtico que las variedades 
que pertenecen al conjunto de hablas que se dan dentro de la comunidad que lo adopta. (2016, p. 88)

Resulta curioso que el último de estos 32 puntos reconoce la necesidad de compilar un manual para el uso de preposiciones.

Es de destacarse que de estos criterios se desprende la gran vitalidad de ambas lenguas, idea que confronta uno de los prejuicios más extendidos en México en el sentido de que hace falta rescatarlas: nada más errado, "no se está perdiendo el idioma. Es cien por ciento la vida de un pueblo [...] no son culturas a punto de extinción" (Arizmendi, Comunicación personal, $1 .^{\circ}$ de marzo de 2018). Como afirma el presbítero Mario Pérez Pérez: "Al pueblo náhuatl lo formamos unos 3 millones y medio de personas. ${ }^{17}$ Del ejercicio de vivir proviene nuestro saber" (Latamat Nemilis, 2018, p. 214). Lo que se hace necesario es dejar de ver "los idiomas indígenas como un signo de atraso": 18 "conocer, valorar y darles su lugar, revalorar. Significa re-co-no-cer. Es decir, darles el valor que tienen" tanto jurídica como pastoralmente (Arizmendi, Comunicación personal, $1 .^{\circ} \mathrm{de}$ marzo de 2018).

$\mathrm{Al}$ igual que el ENTN, el equipo BIA divide entre "Criterios generales" que comprenden preceptos teológicos básicos sobre el origen y la función de la Biblia y criterios específicos propiamente de traducción que engloban bajo el título "Procedimiento". Los primeros oscilan alrede-

17 Cfr. esta cifra con la referida por Arizmendi: "El náhuatl es hablado en México por más de un millón y medio de personas" (2018, p. 29) coincidente con la brindada por el INEGI en 2015.

18 Complementando esta aseveración y ciñéndose a la crítica a la cultura del descarte emprendida en el Papado de Francisco I, en otra parte, el Obispo afirma: "Nuestros pueblos originarios [...] no son desechos en nuestro país. No son descartables. [...] Ellos somos nosotros". (Arizmendi, 2016, p. 31). dor de la idea central de que la Biblia es inspirada por Dios, mas sin embargo detectamos lo que Spivak denomina un "análisis poscolonial de las respuestas de los sujetos marginados que incluye [cierto nivel de] resistencia y refutación, adaptación subversiva y [procesos de reinterpretación]" (apud, Moore y Rivera, 2011, p. 8; traducción propia) porque se admite que "la Biblia es un libro condicionado por el espacio y el tiempo histórico y sociocultural" y, por lo tanto, se hace necesario "trasladar los sentidos genuinos a los lectores de hoy en un vocabulario accesible que permita acceder al mensaje de Dios". Ello da fe del nivel de compromiso hacia el Otro y la puesta en prueba de lo que Spivak llama "tendencias totalizadoras" (ibid, traducción propia) al asumir como necesaria una versión bíblica dirigida específicamente a los hispanoparlantes en los Estados Unidos. Se trata, entonces, de una perspectiva poscolonial que se hace extensiva también para América Latina al encomendarse este encargo al CELAM y definir a los lectores de esta parte del continente como demandantes que requieren ser comprendidos desde un punto de vista minorizado o marginal, ahora no solo lingüística sino también teológicamente.

El "Procedimiento" de BIA deriva de un presupuesto básico de sus "Criterios generales", a saber, que "la Biblia le fue confiada a la comunidad creyente; por lo tanto, debe ser hecha desde la Iglesia y para su servicio". De sus nueve puntos, los dos primeros se refieren a la necesidad de una correcta interpretación del dogma y de la tradición católicas; cuatro de ellos a la atención a géneros y tensiones literarios, campos semánticos y metáforas, es decir, a elementos estílisticos (del segundo al quinto y séptimo) y tres a cuestiones gramaticales (sexto, octavo y noveno). Además, BIA incluye una noción del traductor que se sintetiza en los siguientes aspectos y que puede leerse como un perfil deseable: 
a) Debe estar atento a las estructuras profundas.

b) Interpreta, analiza y transfiere.

c) Es emitente porque reestructura y reformula un sistema apto para reproducir el fenómeno de la comunicación.

d) Comprende la cultura original.

e) Abre un genuino diálogo intercultural, de tal suerte que los lectores actuales a pesar de las distancias culturales, de sus componentes racionales y afectivos propios, tienen la posibilidad de interactuar con el texto.

f) Es capaz de estructurar el texto para darle formas nuevas, sin traicionar el sentido que tiene en su lengua original, en los contextos en que fue escrito.

Sin detenernos en un análisis pormenorizado de las mismas, para no desviarnos de la discusión entablada, siguiendo a Kelly (2002, p. 15) es posible observar que se exige una competencia traductora que contempla fuertemente las competencias temática, cultural y comunicativa-textual, así como la estratégica e instrumental pero deja fuera la psicofisiológica y, sobre todo, la interpersonal que nosotros asociamos directamente con los otros dos equipos cuya interacción sí precisa de percepciones y acuerdos comunitarios. Hay que agregar que los tales no se emiten solo en calidad de receptores sino también de productores textuales.

Conviene preguntarse hasta qué punto los criterios esgrimidos por cada equipo se constituyen en una suerte de códigos deontológicos (es decir, para estimular cierto comportamiento ético) más allá de conformar una guía para la práctica traductiva y responder a criterios gramaticales, ortográficos y editoriales. En la enunciación de estos criterios coexisten tanto elementos éticos (fuertemente ligados a cuestiones teológicas) como metodológicos o prácticos (cfr. Tabla 1).
Los criterios dan cuenta de un "esencialismo estratégico" contemplado desde los debates teológicos como un "espacio epistemológico para aseveraciones de identidad cultural" de los "diferentes" (Moore y Rivera, 2011, p. 10, traducción propia), así como de una "descolonización de la mente" (Moore y Rivera, 2011, p. 56) que va de la mano de una de las más poderosas demandas de la teología india: "Que nos reconozcan el derecho de ser cristianos sin dejar de ser indígenas" (López Hernández, 1998, p. 4). No olvidemos que en una interacción particularmente llena de tensiones, la llamada "opción por los pobres" que ha dado lugar a la "promoción humana de los pueblos originarios" y a la búsqueda de "justicia y reconciliación" (cfr. Arizmendi, 2018) ${ }^{19}$ se ha propiciado desde las altas esferas de la Iglesia Católica.

\section{Las propuestas emanadas del Encuentro de Traductores de la Biblia y la Liturgia a los Idiomas Indígenas}

Las 37 propuestas que se presentan a continuación son altamente relevantes porque sintetizan las preocupaciones de los equipos traductores de lenguas originarias en el momento actual y trazan posibles rutas de acción para grupos que se propongan realizar traducción bíblica y litúrgica. Ocho de estas propuestas no tienen un destinatario específico, 20 están dirigidas a las diferentes diócesis de la CEM, y nueve incluso a esta última. El hecho de que el encuentro sostenido en la Ciudad de México en 2018 haya sido convocado por algunas de sus dimensiones Pastoral Litúrgica, Animación Bíblica de la Pastoral, Doctrina de la Fe, Pastoral de la Cultura y Pastoral Indígenagarantiza una relación vinculante entre los

19 Comunicación personal, $1 .^{\circ}$ marzo de 2018, Teopoxco, Oaxaca, México. 
participantes del mismo (cfr. n. de pie 2) y dichas diócesis, quienes son agentes clave en su posible ejecución. Resulta interesante cómo los participantes distinguen distintos niveles de agencialidad y responsabilidad al emitir sus propuestas. Este juego de fuerzas entre la cúspide convocante y los representantes de las bases en América Latina constituye lo denominado por Spivak como "singularidad ética" e implica acción responsable recíproca, más allá de una benevolencia falaz que refleja al benefactor, y tampoco se queda en la supuesta comprensión de un esencialismo étnico (cfr. Landry y Maclean, 1996, pp. 269-270). Tal singularidad proviene del acto mutuo de escuchar y responder donde los actores pueden ser y hablar y, por ello, relacionarse, lo cual implica un acto de amor (Landry y McLean, 1996; cfr. Moore y Rivera, 2008, p. 8); se trata, por lo tanto, de un activismo agencial, surgido a partir de experiencias traductoras concretas, que puede ser leído como poscolonial. Si se observan las propuestas concretas, se corrobora también que hay pautas para la descolonización fuertemente ligadas con una teología india.

A continuación, sintetizamos y clasificamos las propuestas bajo descriptores del tipo de activismo necesario que proponemos para explicar las demandas. Resulta interesante cómo varias de ellas se traslapan y responden a más de un factor. Si lo consideramos pertinente, añadimos alguna ilustración que, cabe aclarar, no proviene del documento de propuestas; el orden en que las presentamos es propio (Tabla 2).

\section{Conclusiones}

Los procesos de traducción bíblica y litúrgica que hemos seguido dan cuenta de lo que la teología poscolonial denomina "hermenéutica de la liberación" a partir de la última década del siglo xx. Esta consiste en observar el descubrimiento, la apropiación y la recreación de la Biblia en el mundo no bíblico (Pui-Lan, apud Moore y Rivera, 2011, p. 5). Los procesos de traducción confesional permiten atestiguar un activismo político-espiritual derivado de una de las instituciones hegemónicas más importantes en Occidente, y responden a una compleja y continua rearticulación de prioridades al interior de la propia Iglesia Católica, una iglesia comprometida que pide perdón y ha emprendido acciones programáticas para alcanzar una justicia social atenta a la diversidad cultural. Los actores eclesiales han reconocido que "Dios quiere hablar a los pueblos en su propio idioma" (Arizmendi, 2016, p. 31; cfr. López Hernández, 2007 y cELAM, s/f), y que para romper el proyecto imperialista misionero y transitar hacia una verdadera transformación espiritual, se hace imprescindible "no vincular nuestra evangelización [de los pueblos originarios] a un sistema ideológico europeizante y a unas costumbres ajenas a nuestra cultura, y enajenantes de lo identitario propio; si no lo hacemos seguiremos siendo unos 'conquistadores espirituales' con intereses contrarios al Proyecto de Jesucristo, quien vino para que nuestros pueblos 'tengan vida y vida en abundancia"' (Pérez Pérez, 2018, p. 229). Siguiendo a este autor, es menester pasar de una pastoral neocolonial a una descolonizadora, respetar la autoetnicidad y la autodeterminación. Como se resume en Aparecida (CELAM, 2007): descolonizar las mentes, recuperar la memoria histórica, fortalecer espacios y relaciones interculturales para cambiar las estructuras de pecado y estar atentos ante la teología de la prosperidad y el desarrollo global mercantilista.

Ejercer su capacidad de agencia a través de un esencialismo estratégico es crucial tanto para las autoridades eclesiales (ecclesia docens, los que gobiernan, enseñan y edifican) como para quienes son gobernados, reciben enseñanza y 
Tabla 2 Propuestas derivadas del Encuentro de Traductores de la Biblia y la Liturgia a los Idiomas Indígenas agrupadas por descriptores de tipos de demandas o de participación

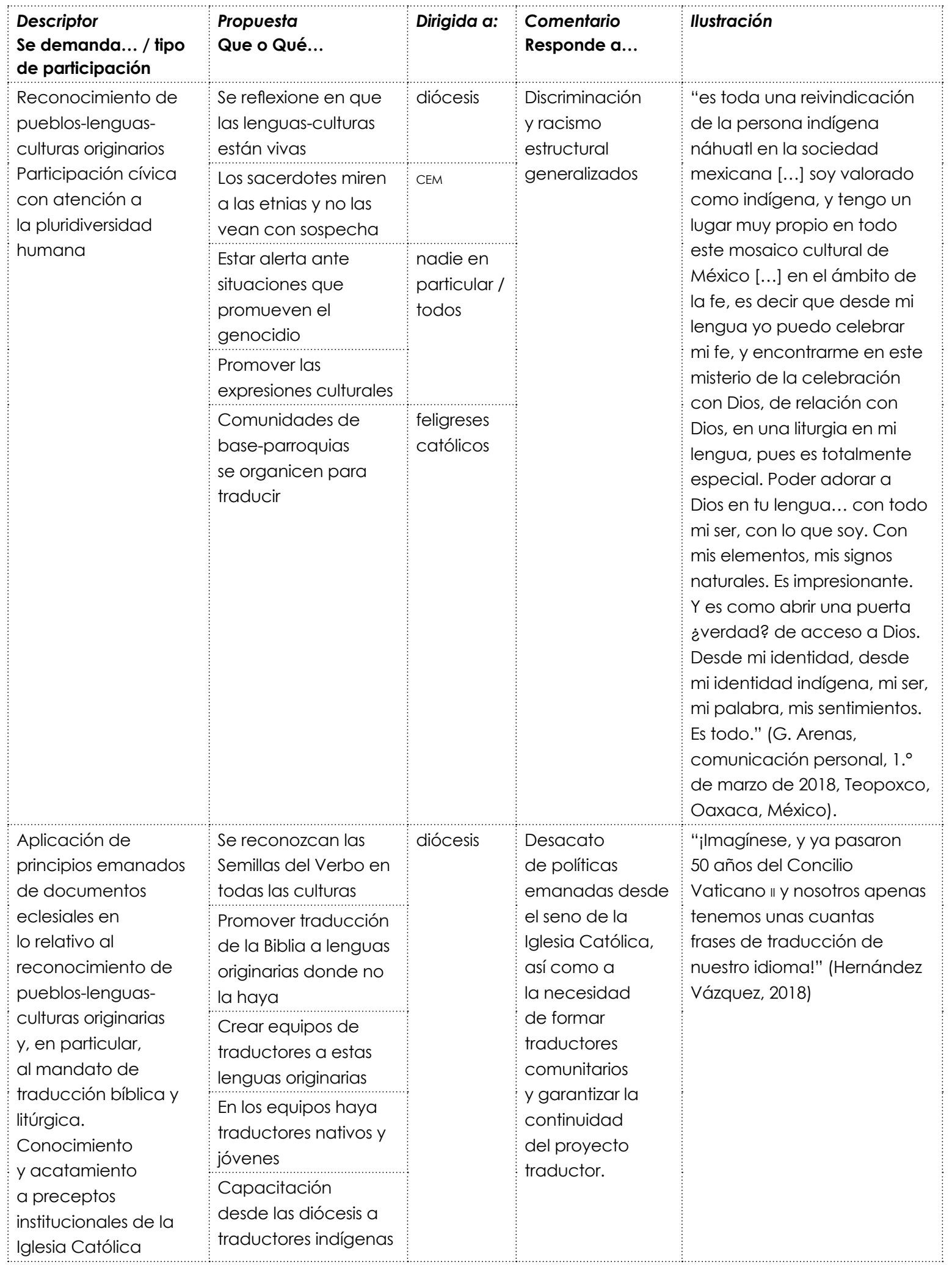




\begin{tabular}{|c|c|c|c|c|}
\hline $\begin{array}{l}\text { Descriptor } \\
\text { Se demanda... / tipo } \\
\text { de participación }\end{array}$ & $\begin{array}{l}\text { Propuesta } \\
\text { Que o Qué... }\end{array}$ & Dirigida a: & $\begin{array}{l}\text { Comentario } \\
\text { Responde a... }\end{array}$ & llustración \\
\hline \multirow{4}{*}{$\begin{array}{l}\text { Participación } \\
\text { de autoridades } \\
\text { eclesiásticas } \\
\text { Conocimiento } \\
\text { y acatamiento } \\
\text { a preceptos } \\
\text { institucionales de } \\
\text { la lglesia Católica } \\
\text { por parte de } \\
\text { sus autoridades } \\
\text { eclesiásticas }\end{array}$} & $\begin{array}{l}\text { El proyecto de } \\
\text { traducción sea } \\
\text { abrazado por cada } \\
\text { iglesia local }\end{array}$ & \multirow[t]{9}{*}{ diócesis } & \multirow{9}{*}{$\begin{array}{l}\text { El desinterés, } \\
\text { la indiferencia } \\
\text { y el rechazo } \\
\text { del proyecto } \\
\text { traductor desde } \\
\text { distintas esferas } \\
\text { eclesiales internas. }\end{array}$} & \multirow{13}{*}{ 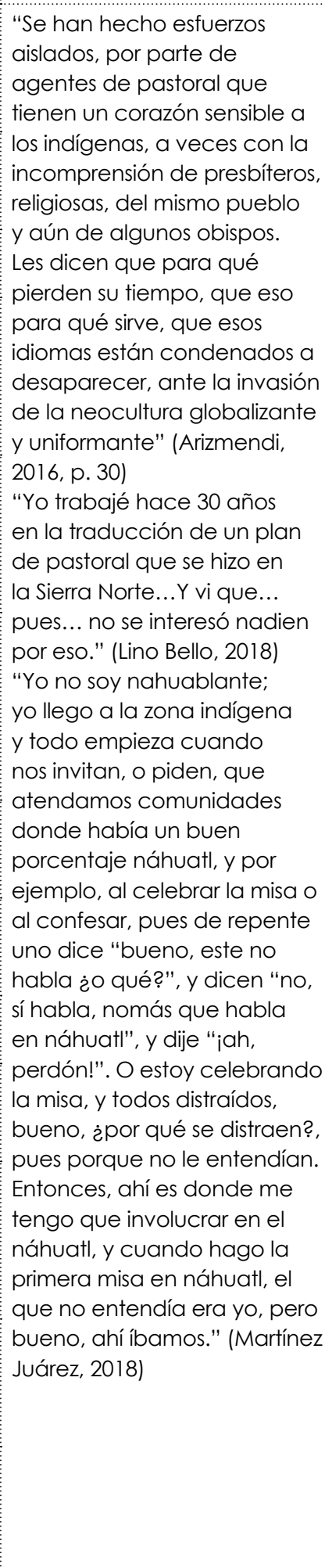 } \\
\hline & $\begin{array}{l}\text { Sensibilización a } \\
\text { agentes de Pastoral } \\
\text { Indígena }\end{array}$ & & & \\
\hline & $\begin{array}{l}\text { Involucrar a los } \\
\text { obispos }\end{array}$ & & & \\
\hline & $\begin{array}{l}\text { Priorizar la Pastoral } \\
\text { Indígena y las } \\
\text { traducciones, } \\
\text { involucrar a } \\
\text { sacerdotes y obispos }\end{array}$ & & & \\
\hline & $\begin{array}{l}\text { Nombramientos de } \\
\text { párrocos por obispos } \\
\text { con conciencia del } \\
\text { respeto a la lengua- } \\
\text { cultura local }\end{array}$ & & & \\
\hline & $\begin{array}{l}\text { Sacerdotes apoyen } \\
\text { a los equipos locales } \\
\text { de traducción y se } \\
\text { pongan en práctica } \\
\text { las traducciones con } \\
\text { apoyo de obispos }\end{array}$ & & & \\
\hline & $\begin{array}{l}\text { Fortalecer } \\
\text { inculturación con } \\
\text { sacerdotes }\end{array}$ & & & \\
\hline & $\begin{array}{l}\text { Sacerdotes no } \\
\text { desanimen a la } \\
\text { comunidad }\end{array}$ & & & \\
\hline & $\begin{array}{l}\text { Evitar y contrarrestar } \\
\text { el clericalismo }\end{array}$ & & & \\
\hline & $\begin{array}{l}\text { Entre los obispos } \\
\text { platiquen más sobre } \\
\text { esto }\end{array}$ & \multirow[t]{4}{*}{ CEM } & & \\
\hline & $\begin{array}{l}\text { Obispos favorezcan } \\
\text { traducción de } \\
\text { catequesis y } \\
\text { formación a pueblos } \\
\text { originarios }\end{array}$ & & & \\
\hline & $\begin{array}{l}\text { Obispos favorezcan } \\
\text { especialización } \\
\text { de sacerdotes en } \\
\text { inculturación }\end{array}$ & & & \\
\hline & $\begin{array}{l}\text { Se otorgue apoyo } \\
\text { económico a } \\
\text { la comunidad } \\
\text { traductora }\end{array}$ & & & \\
\hline
\end{tabular}




\begin{tabular}{|c|c|c|c|c|}
\hline $\begin{array}{l}\text { Descriptor } \\
\text { Se demanda... / tipo }\end{array}$ & $\begin{array}{l}\text { Propuesta } \\
\text { Que o Qué... }\end{array}$ & Dirigida a: & $\begin{array}{l}\text { Comentario } \\
\text { Responde a... }\end{array}$ & Ilustración \\
\hline & $\begin{array}{l}\text { Párrocos cercanos } \\
\text { a sus pueblos y que } \\
\text { apoyen }\end{array}$ & sacerdotes & & \\
\hline \multirow{7}{*}{$\begin{array}{l}\text { Propiciación de } \\
\text { procesos formativos y } \\
\text { de fortalecimiento de } \\
\text { traductores } \\
\text { Participación } \\
\text { institucional desde } \\
\text { las instancias de } \\
\text { autoridad de la lglesia } \\
\text { Católica } \\
\text { Participación de } \\
\text { la comunidad } \\
\text { académica laica }\end{array}$} & $\begin{array}{l}\text { Investigación de las } \\
\text { lenguas habladas } \\
\text { en la diócesis y } \\
\text { continuidad pese al } \\
\text { cambio de obispos y } \\
\text { párrocos }\end{array}$ & \multirow[t]{3}{*}{ diócesis } & \multirow{7}{*}{$\begin{array}{l}\text { La aceptación de } \\
\text { las limitaciones } \\
\text { formativas } \\
\text { de bases } \\
\text { comunitarias } \\
\text { participantes } \\
\text { en los equipos. } \\
\text { Busca establecer } \\
\text { condiciones } \\
\text { propicias para } \\
\text { el proyecto } \\
\text { traductor. }\end{array}$} & \multirow{7}{*}{$\begin{array}{l}\text { "a veces pareciera muy } \\
\text { tardado y muy costoso un } \\
\text { trozo, porque a lo mejor } \\
\text { un trozo de diez renglones } \\
\text { [de traducción] cuesta } 30 \\
\text { personas, tres comidas, tres } \\
\text { días de trabajo" (Martínez } \\
\text { Juárez, 2018) } \\
\text { "el equipo se ha enriquecido, } \\
\text { se ha visto enriquecido por } \\
\text { personas [como lingüistas o } \\
\text { antropólogos] que aportan" } \\
\text { (Pérez Pérez, Comunicación } \\
\text { personal, } 4 \text { de febrero de } \\
\text { 2018) }\end{array}$} \\
\hline & $\begin{array}{l}\text { Crear equipos de } \\
\text { acompañamiento: } \\
\text { antropólogos, } \\
\text { arqueólogos, } \\
\text { lingüistas, biblistas, } \\
\text { dogmáticos, } \\
\text { sacerdotes, laicos que } \\
\text { conozcan las lenguas, } \\
\text { para promover la } \\
\text { inculturación }\end{array}$ & & & \\
\hline & $\begin{array}{l}\text { Crear equipos de } \\
\text { traductores a estas } \\
\text { lenguas originarias }\end{array}$ & & & \\
\hline & $\begin{array}{l}\text { Crear manual de } \\
\text { criterios bíblicos, } \\
\text { litúrgicos y culturales } \\
\text { para hacer } \\
\text { traducciones a } \\
\text { lenguas originarias }\end{array}$ & \multirow[t]{4}{*}{ CEM } & & \\
\hline & $\begin{array}{l}\text { Producir materiales } \\
\text { e instrumentos } \\
\text { que sirvan a los } \\
\text { traductores como } \\
\text { base de su obra }\end{array}$ & & & \\
\hline & $\begin{array}{l}\text { Fomentar encuentros } \\
\text { como este }\end{array}$ & & & \\
\hline & $\begin{array}{l}\text { Continuidad a este } \\
\text { encuentro en otros } \\
\text { lugares }\end{array}$ & & & \\
\hline $\begin{array}{l}\text { Educación teológica } \\
\text { pertinente y } \\
\text { geolocalizada e } \\
\text { involucramiento de } \\
\text { los Seminarios en el } \\
\text { proceso traductoral }\end{array}$ & $\begin{array}{l}\text { Que la formación } \\
\text { religiosa incluya } \\
\text { inculturación y } \\
\text { materias de lengua- } \\
\text { cultura originaria de } \\
\text { la región }\end{array}$ & $\begin{array}{l}\text { Diócesis } \\
\text { CEM }\end{array}$ & $\begin{array}{l}\text { El eurocentrismo } \\
\text { y la ausencia de } \\
\text { contenidos de } \\
\text { lenguas-culturas } \\
\text { originarias en la } \\
\text { malla curricular } \\
\text { de seminarios } \\
\text { de formación } \\
\text { sacerdotal, así } \\
\text { como a la falta } \\
\text { de vinculación } \\
\text { entre seminarios }\end{array}$ & $\begin{array}{l}\text { "En nuestra formación } \\
\text { seminarista había una } \\
\text { desindianización, un } \\
\text { desprecio, el procurar que } \\
\text { a uno se le quitara lo indio } \\
\text { y que uno fuera formado } \\
\text { muy occidentalmente" } \\
\text { (Pérez Pérez, Comunicación } \\
\text { personal, } 4 \text { de febrero de } \\
\text { 2018, Cuautlancingo, Puebla, } \\
\text { México) }\end{array}$ \\
\hline
\end{tabular}




\begin{tabular}{|c|c|c|c|c|}
\hline $\begin{array}{l}\text { Descriptor } \\
\text { Se demanda... / tipo }\end{array}$ & $\begin{array}{l}\text { Propuesta } \\
\text { Que o Qué... }\end{array}$ & Dirigida a: & $\begin{array}{l}\text { Comentario } \\
\text { Responde a... }\end{array}$ & llustración \\
\hline & $\begin{array}{l}\text { Acompañamiento } \\
\text { a la Pastoral de los } \\
\text { Pueblos Originarios } \\
\text { desde los seminarios }\end{array}$ & Seminarios & \multirow[t]{2}{*}{$\begin{array}{l}\text { y políticas de } \\
\text { ubicación de } \\
\text { párrocos. }\end{array}$} & \multirow{2}{*}{$\begin{array}{l}\text { "[En el seminario] Yo me tuve } \\
\text { que quitar mis huaraches y } \\
\text { aprender a usar los zapatos. } \\
\text { [...] Verdaderamente en } \\
\text { el Seminario nos forman } \\
\text { de una manera europea" } \\
\text { (Hernández Vázquez, 2018) }\end{array}$} \\
\hline & $\begin{array}{l}\text { Apoyar vocaciones } \\
\text { indígenas }\end{array}$ & $\begin{array}{l}\text { nadie en } \\
\text { particular / } \\
\text { todos }\end{array}$ & & \\
\hline $\begin{array}{l}\text { Ecumenismo y } \\
\text { relaciones con otras } \\
\text { esferas de la sociedad }\end{array}$ & $\begin{array}{l}\text { Comunión con } \\
\text { instituciones civiles y } \\
\text { gubernamentales }\end{array}$ & $\begin{array}{l}\text { nadie en } \\
\text { particular / } \\
\text { todos }\end{array}$ & $\begin{array}{l}\text { Divisiones } \\
\text { estructurales } \\
\text { entre esferas } \\
\text { laica y religiosa. } \\
\text { Divisiones } \\
\text { religiosas }\end{array}$ & $\begin{array}{l}\text { El mandato cultural no solo } \\
\text { para sacerdotes y misioneros, } \\
\text { sino para todos los creyentes, } \\
\text { incluso no católicos (cfr. Pérez } \\
\text { Pérez, 2018) } \\
\text { "Pues yo creo que un fruto de } \\
\text { este proceso traductológico } \\
\text { de este equipo, que nos lleva } \\
\text { a esa mayor apertura, es } \\
\text { decir, el oírnos, eso ya es estar } \\
\text { abriendo nuestra existencia } \\
\text { y muchas cosas más a otras } \\
\text { realidades." (Martínez Juárez, } \\
2018 \text { ) }\end{array}$ \\
\hline
\end{tabular}

Elaboración: Villegas (2019)

sacramentos (ecclesia audiens). La traducción bíblica y litúrgica desde y para los pueblos originarios o inmigrantes - ir pronunciando lo que se piensa en la lengua propia (Pérez Pérez, 2018, p. 84) - cumple un papel preponderante en esta empresa descolonizadora, pues "si la traducción no nos conduce a la reformulación o la transformación del ser, no se dará un cambio político real" (Spivak apud Moore y Rivera, 2011, p. 117, traducción propia).

Traducir la Biblia y la liturgia a los idiomas nativos no es por afición académica, curiosidad etnológica, dinero, publicidad eclesial o demagogia, sino para que el pueblo tenga vida, la vida que Dios mismo le ha dado. [...] La Iglesia, a pesar de sus limitaciones y errores del pasado y del presente, quiere estar cer- ca de estos pueblos, amenazados en su misma existencia, para que vivan su identidad con confianza y seguridad. (Arizmendi, 2016, p. 31)

Incluso los procesos de legitimación del trabajo traductoral de los pueblos originarios están avanzando a pasos acelerados a través de la autonomía otorgada a instancias locales que reciben el voto de confianza de Roma. Más allá de ilustrar los indiscutibles resultados obtenidos por cada equipo traductor, tales como la autorización del NT-BIA, la Biblia en tseltal y el oficio litúrgico en náhuatl (Zendejas, 2016), es importante reconocer puntos de convergencia, tanto en sus formas organizativas y de trabajo como en las demandas generadas colectivamente. En cuanto a las primeras, des- 
taca el deseo de apegarse a los lineamientos eclesiales, pero hay un contraste entre aprovechar las libertades otorgadas por un documento como el Varietates Legitimae o seguir al pie de la letra la tradición magisterial; mientras BIA se erige como guardián escritural único, Bachajón y ENTN han logrado también importantes avances en la inculturación, logrando por ejemplo, incluir el enfloramiento y sahumerio o "abrirle la boca al bautizado" (Zendejas, 2016). Se hace evidente que ya existe una experiencia avalada por años de trabajo que los equipos traductores nacientes pueden aprovechar y que se refleja en las demandas colectivas, entre las que sobresalen la sensibilización y la articulación pertinente de la ecclesia docens, así como una ciudadanización ligada a la espiritualidad.

Los documentos generados por cada equipo y compartidos en el Encuentro de Traductores, junto con las propuestas derivadas de este, se constituyen en metanarrativas posibilitadoras de agencia y empoderamiento (cfr. enabling metanarratives, Spivak en Moore y Rivera, 2011, p. 6) que, a su vez, dan cuenta de su capacidad para producir una epistemología propia geolocalizada:

Quienes fueron excluidos de la pertenencia a la Iglesia por sus creencias politeístas, son hoy sujetos eclesiales de pleno derecho, [...] sujetos sacramentales [...] sujetos teológicos que reformulan creativamente la fe, la esperanza y la caridad, hablan de Dios y a Dios, a partir de experiencias personales y comunitarias de sufrimiento y de lucha en su propio lenguaje, con sus propias categorías, en plena sintonía con la Tradición y con sus tradiciones religiosas y culturales. (Tamayo, 2013, p. 20)

De la investigación realizada se desprende también que, como afirma Pérez Pérez, "todo es una pedagogía" (2018, p. 16), pues aun sin ser el propósito central de estos equipos, se han producido procesos formativos en la es- crituración de lenguas orales, en el manejo de herramientas para la escritura y, por supuesto, en la adquisición de distintas habilidades y competencias para traducir, entre las cuales destacan normas para la estandarización, la creación de paratextos de distinta índole, el apoyo en fuentes autorizadas y el reconocimiento de la necesidad de asesoría interdisciplinaria externa. Adjetivar como activista la traducción de estos equipos equivale a reconocer los esfuerzos de variopintos actores que van desde la cúspide eclesial hasta las bases comunitarias pasando por obispos, mujeres consagradas, sacerdotes y seminaristas, en suma, "hombres y mujeres progresistas"; con "¡esperanza para todas y todos los que luchan hoy!" (Zendejas, 2016).

\section{Referencias}

Arizmendi, F. (2016). Evangelio que transforma. Artículos 2015. México: Ediciones CEM.

Arizmendi, F. (2017). Clarificación de términos. Ponencia presentada en el Encuentro Latinoamericano y Caribeño de Comisiones Episcopales de Liturgia sobre inculturación de la liturgia, del celam. San Cristóbal de las Casas, Chiapas, México.

Arizmendi, F. (2018). Pueblos originarios y magisterio eclesial. México: Ediciones CEM.

Arizmendi, F. (2019, 8 de abril). Obispo Arizmendi señala aciertos y fallas en la Iglesia. Diario de Yucatán. Recuperado de www.yucatan.com.mx/mexico/obispo-arizmendi-senala-aciertos-y-fallas-en-la-iglesia

Biblia de la Iglesia en América. Nuevo Testamento. (2015). México: PPC. Recuperado de www. nuevotestamento-bia.com/bia-la-biblia-del-siglo-xxi-para-discipulos-misioneros/, consultado el 10 de marzo 2019.

United States Census Bureau (2015). Detailed languages spoken at homes and ability to speak English for the population 5 years and over: 20092013. Recuperado de www.census.gov/data/ 
tables/2013/demo/2009-2013-lang-tables. html, consultado el 3 de marzo 2019.

Calefato, P. (2008). Espacio continuo de transformación: la mirada semiótica sobre la traducción cultural. (A. Mirizio, trad.). deSignis, 12, 135-144.

Carbonell I Cortés, O. (1999). Traducción y cultura. De la ideología al texto. Salamanca: Colegio de España.

CELAM (s/f). Caminar de la pastoral indígena y de la teología india en América Latina, manuscrito inédito.

Celam (2007). Documento conclusivo Aparecida de la $v$ Conferencia General del Episcopado Latinoamericano y del Caribe (2. ${ }^{\text {a }}$ Ed.). Bogotá: CELAM.

Chow, R. (2008). Traducción como 'resistencia cultural'. (M. de Marco, trad.). deSignis, 12, 145-158.

Concilio Vaticano II (1963). Sacrosanctum Concilium. Constitución sobre la sagrada liturgia. Roma: Vaticano.

Concilio Vaticano II (1965). Gaudium et Spes. Constitución pastoral sobre la Iglesia en el mundo actual. Roma: Vaticano.

Congregación para el Culto Divino y la Disciplina de los Sacramentos. (1994). Instrucción Varietates Legitimae. Recuperado de http://cantoliturgico.org/index.php/ documentos/item/4854-varietates-legitimae-congregacion-para-el-culto-divino-y-la-disciplina-de-los-sacramentos-25-01-1994.

Constantino Reyes, J. (2012). Algunos momentos en los estudios sobre la traducción: su punto de contacto con los estudios culturales y la traducción con enfoque de género. En A. de Teresa (Coord.), Tránsitos y umbrales en los estudios culturales (pp. 125-142). México: unAm-Bonilla Artigas Editores.

Dietz, G. y Mateos Cortés, L. S. (2019). ¿El racismo como problema, la interculturalidad como solución? El caso de la Universidad Veracruzana en México. Iniciativa para la erradicación del racismo en la educación superior, Colección Apuntes No. 2. Buenos Aires: untref. Recuperado de http://unesco.untref.edu.ar/pdf/apuntes-2-gunther-dietz-y-laura-mateos-el-racismo-como-problema-la-interculturalidad-como-solucin.pdf

González Treviño, A. E. (2012). Dichas y desdichas de la fragmentación. En A. de Teresa, Tránsitos y umbrales en los estudios culturales (pp. 19-31). México: UNAM-Boni1la Artigas Editores.

Hasler, A., Antonio, F. y Martínez Juárez, C. (2017). Criterios lingüisticos para una escritura estándar. Documento de trabajo. Equipo Nacional de Traductores Nahuas de la Conferencia del Episcopado Mexicano. México.

Hurtado Albir, A. (2016). Traducción y traductología. Introducción a la traductología (8. ${ }^{a}$ Ed.). Madrid: Cátedra.

INALI. (2008, 14 de enero). Catálogo de las lenguas indígenas nacionales: variantes lingüisticas de México con sus autodenominaciones y referencias geoestadísticas. Diario Oficial de la Federación, México.

INEGI. (2010). Cuéntame. Información por entidad. Chiapas. Población y diversidad. http://cuentame.inegi.org. $\mathrm{mx} / \mathrm{mono}-$ grafias/informacion/chis/default.aspx?tema $=$ me\&e $=07$ y http://cuentame. inegi.org. $\mathrm{mx} / \mathrm{monografias/informacion/}$ chis/poblacion/diversidad.aspx?tema $=$ me\&e=07. Consultado el 23 de junio 2019.

Juan Pablo II. (1985). Slavorum Apostoli. Carta encíclica. Vaticano: Libreria Editrice Vaticana.

Kelly, D. A. (2002). Un modelo de competencia traductora: bases para el diseño curricular. Puentes, 1, 9-20.

Landry, D. y MacLean, G. (Eds.) (1996). The Spivak Reader. Nueva York y Londres: Routledge.

Lino Bello, C. (2018). Entrevista por F. Antonio, 1 junio, Cuautlancingo, Puebla.

López Hernández, E. (s/f). La Biblia y los pueblos indigenas de América. Algunos puntos 
que debemos repensar en las iglesias, manuscrito inédito. (Circuló en Congreso de Pastoral de Pueblos Originarios organizado por la CEM, Mérida, Yucatán, México, agosto, 2018).

López Hernández, E. (1998). Fuerza espiritual y teológica de los pueblos amerindios después de la Conquista, manuscrito inédito. (Circuló en Congreso de Pastoral de Pueblos Originarios organizado por la CEM, Mérida, Yucatán, México, agosto 2018.)

López Hernández, E. (2007). Teología india, un balance después de Aparecida. México: cenami.

Martín Pérez, F. (2015, 16 de enero). Traducen NT al tsotsil, tseltal, tojolabal y chol. Semanario Paralelo. Recuperado de https:// www.chiapasparalelo.com/\%20noticias/ chiapas/2015/01/traducen-nuevo-testamento-al-tsotsil-tseltal-tojolabal-y-chol/ Consultado el 3 de abril de 2019.

Martínez Juárez, C. (2018). Entrevista por Antonio y Villegas, 1 marzo, Teopoxco, Oaxaca, México.

Mignolo, W. D. (1996). Herencias coloniales y teorías postcoloniales. En B. González Stephan, Cultura y tercer mundo. Cambios en el saber académico (pp. 99-136). Venezuela: Nueva Sociedad.

Mignolo, W. D. (2009). Epistemic disobedience, independent thought and decolonial freedom. Theory, Culture \& Society, 26(7-8), 159-181.

Moore, S. D. y Rivera, M. (eds.) (2011). Planetary loves: Spivak, postcoloniality, and theology. Nueva York: Fordham University Press.

Moreno Cabrera, J. C. (2016) La dignidad e igualdad de las lenguas. Crítica a la discriminación lingüística (2. ${ }^{\mathrm{a}}$ Ed.). Madrid: Alianza.

Nida, E. (1964/2006). Principles of correspondence (pp. 153-167). En L. Venuti (Ed.), The translation studies reader. Nueva York: Routledge.

Nuestro México (2011). Bachajón - Chiapas. Recuperado de http://www.nues-
tro-mexico.com/Chiapas/Chilon/Bachajon/ Consultado el 23 de junio 2019.

Olarte, E. (2010). La educación bilingüe en contextos plurilingües. En R. Morales Garza (coord.), Transformación posible de la educación para la niñez indígena. Contextos, alianzas y redes (pp. 309-372). México: SEP / Subsecretaría de Educación Básica.

Papa Francisco. (2013). Evangelii Gaudium. Exhortación apostólica sobre el anuncio del Evangelio en el mundo actual. Vaticano: Libreria Editrice Vaticana.

Pérez Pérez, M. (2018). Latamat Nemilis. Haciendo misionología y teología para el bien con-vivir de los pueblos de la Sierra Norte de Puebla. México: edición de autor.

Santos, B. de S. (2006). La sociología de las ausencias y la sociología de las emergencias: para una ecología de saberes. En Renovar la teoría crítica y reinventar la emancipación social (pp. 13-41). Buenos Aires: CLACSO.

Santos, B. de S. (2015). Construyendo la contrahegemonía: traducción intercultural entre los movimientos sociales. En R. Sandoval (ed.), Pensar desde la resistencia anticapitalista y la autonomía (pp. 27-44). México: CIESAS.

Sapir, Edward. (1954). El lenguaje. (M. y A. Alatorre, trads.). México: FCE.

Sbahpahcal. Misal romano traducido a lengua tseltal (Ed. bilingüe español-tseltal. 3 tomos). (2018). México: CEM.

Siller Acuña, C. L. (s/f). Guadalupe: Luz y cambio de nuestra realidad. México: s/ed. (Circuló en Congreso de Pastoral de Pueblos Originarios organizado por la CEM, Mérida, Yucatán, México, agosto 2018).

Spivak, G. C. (2017). Una educación estética en la era de la globalización. (C. M. Fraga, I. Villegas y G. Dietz, trads.). México: Siglo XXI Editores, UNAM, UAM, Palabra de Clío y UDLAP.

Tamayo, J. J. (2013). Las alteridades negadas, nuevos sujetos teológicos en América Latina. 
Madrid: manuscrito inédito. (Circuló en el XviI Taller del ENTN, Hueyapan, Morelos, México, junio 2017).

Walsh, C. (2013). Lo pedagógico y lo decolonial: Entretejiendo caminos (introducción). En C. Walsh (ed.), Pedagogías decoloniales. Prácticas insurgentes de resistir, (re) existir y (re)vivir (pp. 23-68) (tomo I). Serie Pensamiento Decolonial. Quito: Abya-Yala.

Zendejas, M. (2016, 3 de marzo). Misas en náhuatl. Letras Libres, https://www. letraslibres.com/mexico-espana/misas-en-nahuatl

Cómo citar este artículo: Villegas-Salas, L. I. y Dietz, G. (2019). Criterios de traducción bíblica-litúrgica al tseltal, al náhuatl y al español minorizado: un paradigma de traducción activista. Mutatis Mutandis. Revista Latinoamericana de Traducción, 12(2), 357-385. DoI: 10.17533/udea.mut. $\mathrm{v} 12 \mathrm{n} 2 \mathrm{a} 02$ 